\author{
دراسة تحليلية للأستثمار الزراعى فى مصر \\ مهابه عبد المعطى السيد أحمد مهابه - محمد على محمد سكر

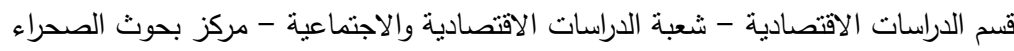

Corresponding author: mahaba_agr11@yahoo.com

مقدمة :

تستلزم عملية التخطيط الأقتصادى تحديد الأهداف الأقتصادية بدقة وتقدير أحتياجاتها الأستثمارية وتوزيعها على مختلف القطاعات الاقتصادية

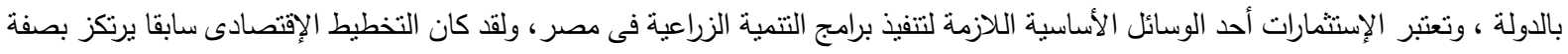

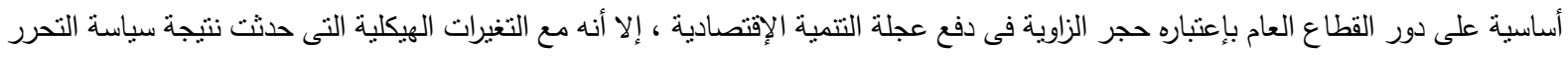

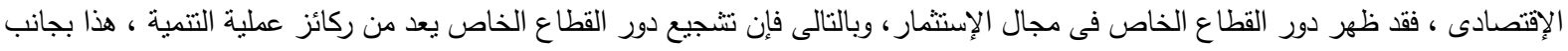

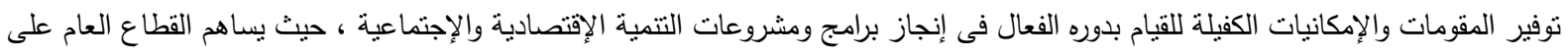

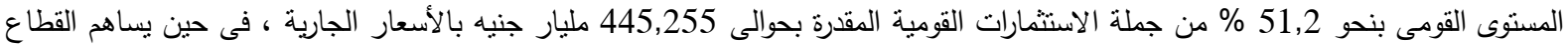

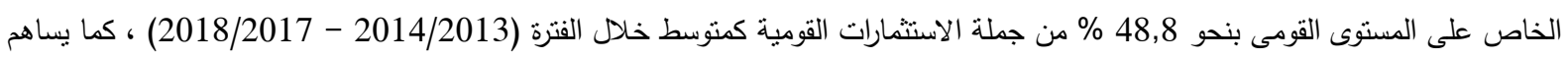

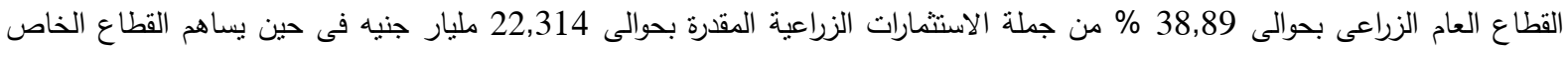

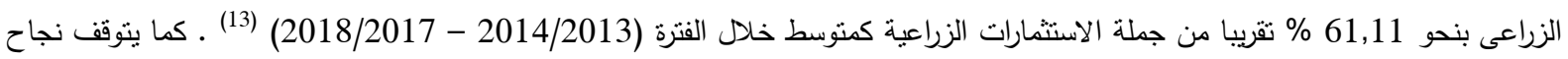

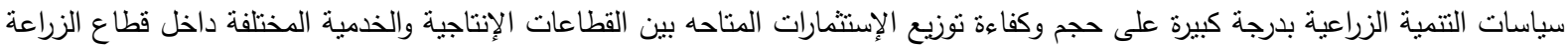

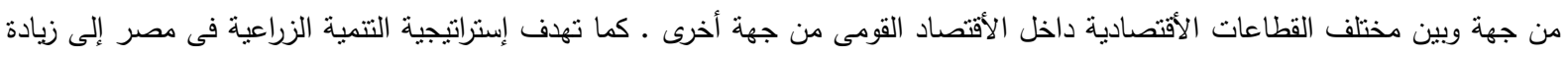

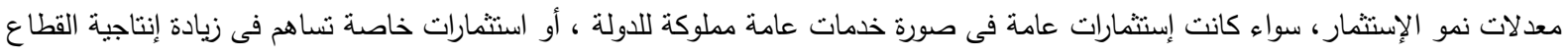

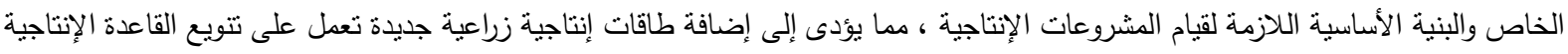
داخل البنيان الإقتصادى القومى •

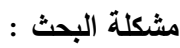
يواجه القطاع الزراعى العديد من المشاكل الاقتصادية لعل من أهمها عدم كفاية الأستثمارات الموجهة لهذا القطاع ، حيث قدرت الأستثارات

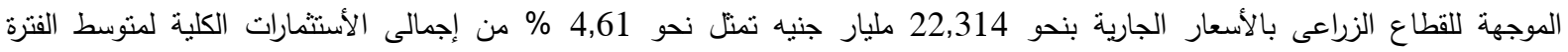

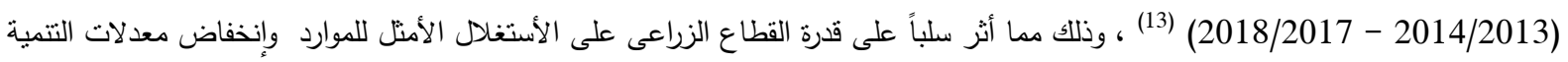

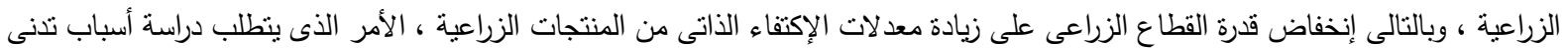
هذه الإنتثمارات . هاف البحث : يهدف البحث إلى تحليل هيكل الاستثمارات الزراعية الكلية ومن ثم التعرف على دور الإستثمارات الزراعية فى تتمية القطاع الزراعى المصرى وذللك من خلال دراسة الأهداف التالية :

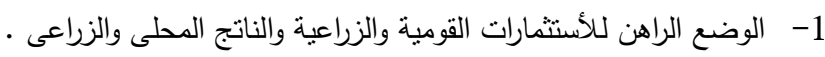

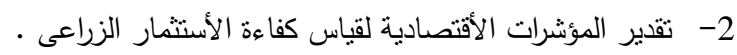

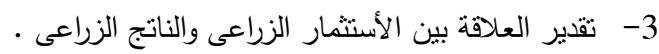
4- - تحديد أهم العوامل المؤثرة على الإستثمار الزراعى .

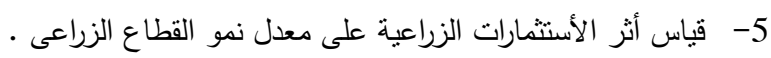
الطريقة البحثية ومصادر البيانات :

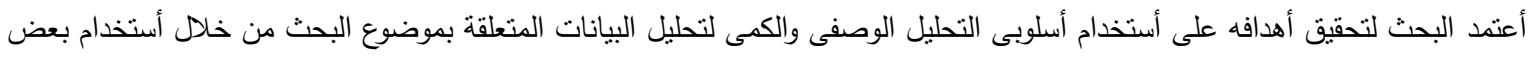

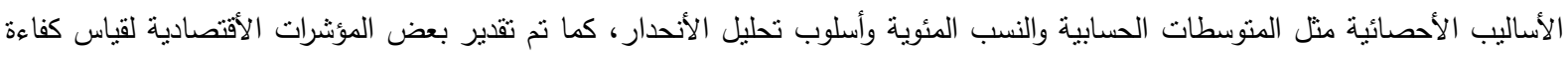
الأستثارات الزراعية ، وتم أستخدام دالة مرونة الإحلال الثابتة Constant Elasticity of Substitution (CES) فى تقدير العلاقة بين الأستثمار

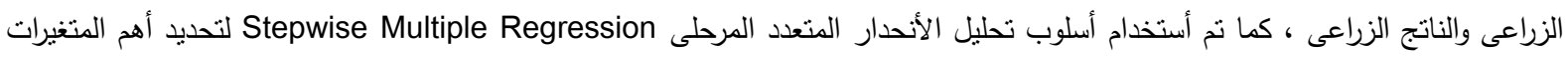
الأقتصادية المؤثرة على الإستثمار الزراعى فى مصر ،هذا بالأضافة إلى أستخدام Harrod - Domar Growth Model لقياس أثثر الأستثمارات 
الزراعية على معدل نمو القطاع الزراعى ، وأعتمد البحث على البيانات الثانوية المتاحة من الجهاز المركزى للتعبئة العامة والأحصاء ووزارة التخطيط والمتابعة والإصلاح الإدارى والبنك المركزى المصرى والبنك الأهلى المصرى ، بالإضافة إلى الدراسات والمراجع المتعلقة بموضوع البحث . النتائج البحثية ومناقثتها : أولاً : تطور الأستثمارات القومية والززاعية والناتج المحلى والزراعى بالأسعار الحقيقية فى جمهورية مصر العريبة خلال الفترة (1996/1995: (2018/2017

1 - تطور الأستثمارات القومية العامة : بدراسة تطور الأستثمارات القومية العامة بالأسعار الحقيقية خلال الفترة (1996/1995 - 2018/2017) بالجدول رقم (1) تبين أن الأستثمارات القومية العامة قد بلغ حدها الأدنى حوالى 26,904 مليار جنيه عام 2001/2000 تنثل حوالى 49,3 \% من إلجمالى الأستثارات القومية لنفس

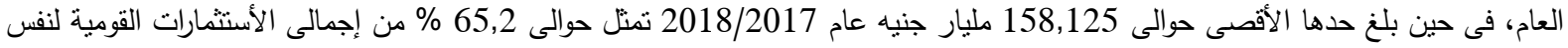

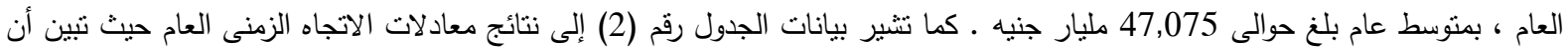

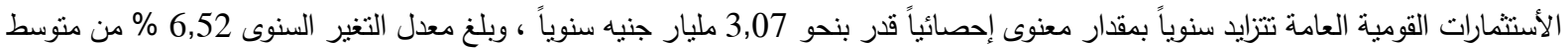

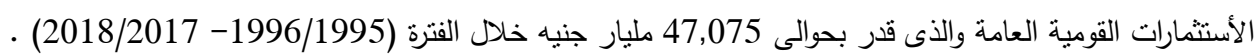
2- تطور الأستثمارات القومية الخاصة :

بدراسة تطور الأستثمارات القومية الخاصة بالأسعار الحقيقية خلال الفترة (1996/1995 - 2018/2017) بالجدول رقم (1) تبين أن

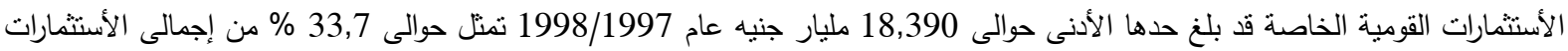

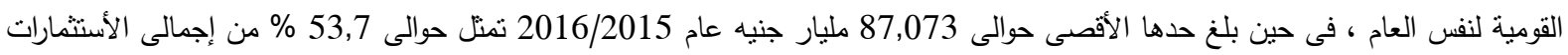
القومية لنفس العام ، بمتوسط عام بلغ حوالى 48.134 مليار جنيه ـ كما تبين من الجدول رقم (2) أن الأستثمارات القومية الخاصة تنزايد سنوياً

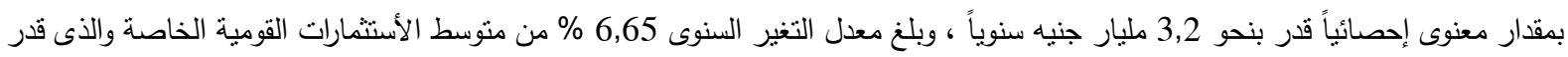

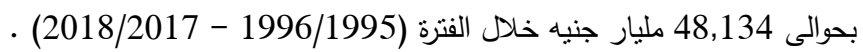

3- تطور إجمالى الأستثمارات القومية : وبدراسة تطور إجمالى الأستثمارات القومية بالأسعار الحقيقية خلال الفترة (1996/1995 - 2018/2017) تبين من الجدول رقم (1) أن

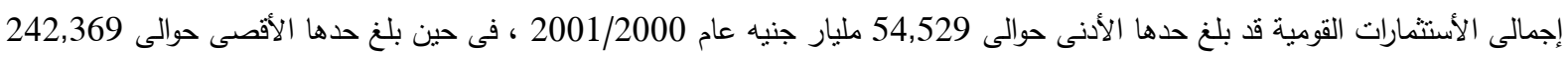

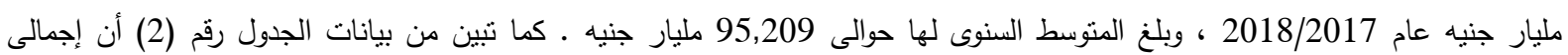
الأستثمارات القومية تنزايد سنوياً بمقار معنوى إحصائياً قدر بنحو 6,27 مليار جنيه سنوياً ، وبلغ معدل التغير السنوى 6,59 هائل

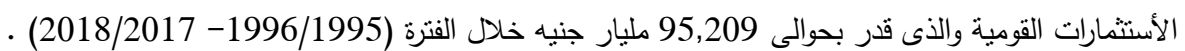

4- تطور الأستثمارات الزراعية العامة :

ثبين من الجدول رقم (1) أن الأستثارات الزراعية العامة قد بلغ حدها الأدنى حوالى 1,172 مليار جنيه عام 2012/2011 تمثل حوالى 49,8

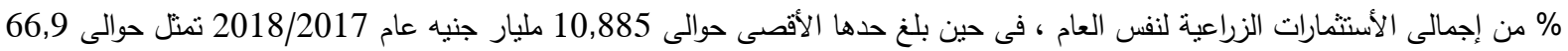

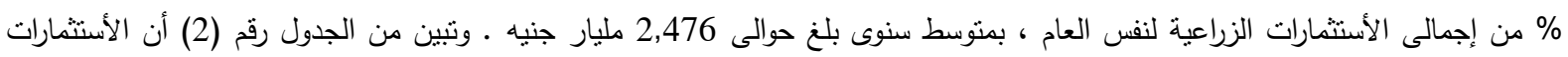

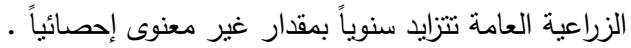
5- 5 تطور الأستثمارات الزراعية الخاصة : وتبين من الجدول رقم (1) أن الأستثمارات الزراعية الخاصة قد بلغ حدها الأدنى حوالى 1,183 مليار جنيه عام

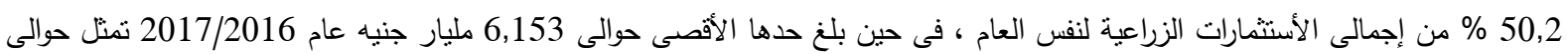

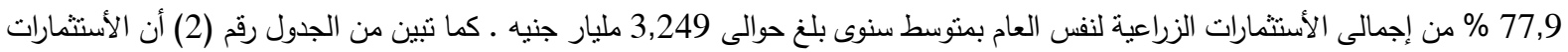

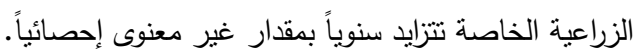
6- 6 تطور أجمالى الأستثمارات الزراعية :

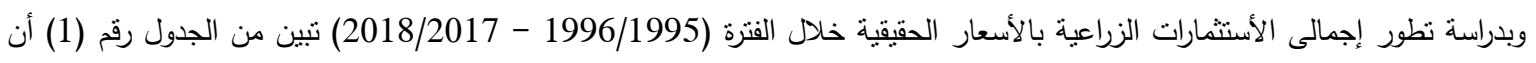

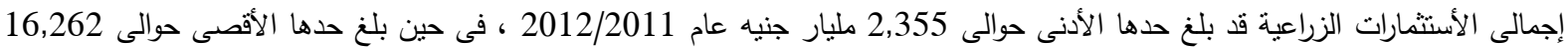
مليار جنيه عام 2018/2017 ، وبلغ المنوسط السنوى لها حوالى 5,725 مليار جنيه ـ وتينين من بيانات الجدول رقم (2) أن إجمالى الألى الأستثارات الزراعية نتزايد سنوياً بمقدار غير معنوى إحصائياً. 
جدول 1. تطور الأستثارات القومية والزراعية والناتج المحلى الأجمالى والزراعى بالأسعار الحقيقية فى جمهورية مصر العربية خلال الفنرة (1996/1995- 2018/2017)

(القيمة : مليار جنيه)

\begin{tabular}{|c|c|c|c|c|c|c|c|c|c|c|c|c|}
\hline \multicolumn{6}{|c|}{ الناتج } & \multicolumn{6}{|c|}{ الأستثمارات } & \multirow{3}{*}{ السنه } \\
\hline \multicolumn{3}{|c|}{ الزراعى } & \multicolumn{3}{|c|}{ المحلى } & \multicolumn{3}{|c|}{ الزراعية } & \multicolumn{3}{|c|}{ القومية } & \\
\hline الإجمالى & خاص & عام & الإجمالى & خاص & عام & الإجمالى & خاص & عام & الإجمالى & خاص & عام & \\
\hline 36.968 & 36.772 & 0.196 & 214.185 & 140.186 & 73.999 & 4.484 & 2.412 & 2.072 & 54.888 & 20.700 & 34.188 & $1995 / 1996$ \\
\hline 38.654 & 38.480 & 0.174 & 227.988 & 150.498 & 77.490 & 4.792 & 2.513 & 2.279 & 63.203 & 26.042 & 37.161 & $1996 / 1997$ \\
\hline 40.578 & 40.405 & 0.173 & 237.109 & 162.517 & 74.592 & 7.250 & 3.383 & 3.867 & 54.531 & 18.390 & 36.140 & $1997 / 1998$ \\
\hline 42.954 & 42.778 & 0.176 & 248.041 & 172.447 & 75.594 & 7.390 & 3.971 & 3.419 & 56.199 & 26.711 & 29.488 & 1998/1999 \\
\hline 46.027 & 45.845 & 0.182 & 274.942 & 190.607 & 84.335 & 7.084 & 4.291 & 2.793 & 56.134 & 26.921 & 29.213 & $1999 / 2000$ \\
\hline 47.225 & 47.040 & 0.185 & 285.199 & 196.226 & 88.973 & 7.030 & 4.553 & 2.477 & 54.529 & 27.625 & 26.904 & $2000 / 2001$ \\
\hline 49.623 & 49.577 & 0.046 & 301.437 & 198.073 & 103.364 & 8.157 & 5.014 & 3.142 & 57.396 & 27.075 & 30.321 & $2001 / 2002$ \\
\hline 51.455 & 51.414 & 0.041 & 314.931 & 199.130 & 115.801 & 5.162 & 2.566 & 2.596 & 54.907 & 27.127 & 27.780 & $2002 / 2003$ \\
\hline 50.037 & 50.000 & 0.038 & 329.714 & 205.233 & 124.481 & 5.462 & 2.890 & 2.572 & 57.483 & 26.806 & 30.676 & $2003 / 2004$ \\
\hline 48.432 & 48.397 & 0.035 & 325.813 & 201.073 & 124.739 & 4.773 & 2.734 & 2.039 & 62.045 & 29.858 & 32.188 & $2004 / 2005$ \\
\hline 47.030 & 47.022 & 0.007 & 334.259 & 201.518 & 132.740 & 4.627 & 3.016 & 1.610 & 66.571 & 38.148 & 28.423 & $2005 / 2006$ \\
\hline 54.675 & 54.665 & 0.010 & 388.586 & 238.264 & 150.322 & 4.262 & 2.931 & 1.331 & 84.973 & 53.224 & 31.749 & $2006 / 2007$ \\
\hline 55.471 & 55.460 & 0.010 & 419.474 & 255.386 & 164.088 & 3.959 & 2.562 & 1.397 & 97.860 & 63.306 & 34.554 & $2007 / 2008$ \\
\hline 68.325 & 68.313 & 0.012 & 501.378 & 310.114 & 191.263 & 3.461 & 2.078 & 1.384 & 99.431 & 48.156 & 51.275 & $2008 / 2009$ \\
\hline 76.306 & 76.293 & 0.013 & 545.429 & 342.015 & 203.414 & 3.196 & 1.832 & 1.364 & 109.896 & 60.079 & 49.817 & $2009 / 2010$ \\
\hline 84.275 & 84.260 & 0.015 & 580.525 & 361.379 & 219.146 & 3.029 & 1.577 & 1.452 & 101.518 & 62.788 & 38.730 & $2010 / 2011$ \\
\hline 82.761 & 82.706 & 0.055 & 751.023 & 484.057 & 266.966 & 2.355 & 1.183 & 1.172 & 107.874 & 67.303 & 40.571 & $2011 / 2012$ \\
\hline 90.608 & 90.545 & 0.063 & 831.487 & 534.858 & 296.630 & 3.622 & 2.347 & 1.274 & 104.373 & 62.945 & 41.427 & $2012 / 2013$ \\
\hline 102.414 & 102.342 & 0.072 & 935.363 & 596.911 & 338.453 & 4.931 & 3.173 & 1.758 & 112.422 & 65.571 & 46.851 & $2013 / 2014$ \\
\hline 119.682 & 119.596 & 0.086 & 1062.942 & 701.727 & 361.216 & 5.765 & 3.525 & 2.241 & 143.429 & 79.907 & 63.522 & $2014 / 2015$ \\
\hline 131.830 & 131.733 & 0.097 & 1105.651 & 763.831 & 341.819 & 6.730 & 4.647 & 2.083 & 162.076 & 87.073 & 75.003 & $2015 / 2016$ \\
\hline 143.900 & 143.797 & 0.104 & 1231.067 & 849.577 & 381.489 & 7.894 & 6.153 & 1.741 & 185.701 & 77.075 & 108.627 & $2016 / 2017$ \\
\hline 167.409 & 167.287 & 0.122 & 1456.608 & 1010.144 & 446.463 & 16.262 & 5.378 & 10.885 & 242.369 & 84.244 & 158.125 & $2017 / 2018$ \\
\hline 72.897 & 72.814 & 0.083 & 561.007 & 368.077 & 192.930 & 5.725 & 3.249 & 2.476 & 95.209 & 48.134 & 47.075 & المتوسط \\
\hline
\end{tabular}

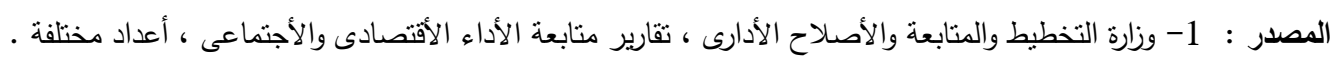

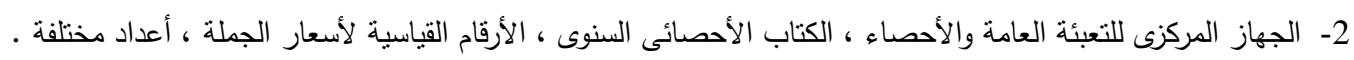


جدول 2. معادلات الأتجاه الزمنى العام لتطور الأستثمارات القومية والزراعية والناتج المحلى الأجمالى والزراعى بالأسعار الحقيقية فى جمورية

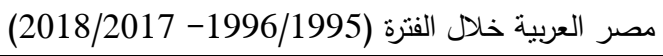

\begin{tabular}{|c|c|c|c|c|c|c|}
\hline معدل التغير & المتوسط & & & المعادلات & \multirow{2}{*}{\multicolumn{2}{|c|}{ المتغير }} \\
\hline السنوى \% & & $\mathbf{F}$ & $\mathbf{R}^{2}$ & & & \\
\hline 6.52 & 47.075 & 18.05 & 0.46 & $\begin{array}{r}\hat{\mathrm{Y}}_{\mathrm{t}}=10.23+3.07 \mathrm{X}_{\mathrm{t}} \\
(4.25)^{* *}\end{array}$ & العامة & الأستثمارات \\
\hline 6.65 & 48.134 & 213.38 & 0.91 & $\begin{array}{r}\hat{Y}_{t}=9.7+3.2 X_{t} \\
(14.61)^{* *}\end{array}$ & الخاصة & $\begin{array}{c}\text { (مليار جنية) } \\
\text { (القومية }\end{array}$ \\
\hline 6.59 & 95.209 & 63.59 & 0.75 & $\begin{array}{r}\hat{Y}_{\mathrm{t}}=19.93+6.27 \mathrm{X}_{\mathrm{t}} \\
(7.97)^{* * *}\end{array}$ & الأجمالى & \\
\hline 1.28 & 2.476 & 0.25 & 0.01 & $\begin{array}{r}\hat{Y}_{t}=2.1+0.03 X_{t} \\
(0.5)\end{array}$ & العامة & الأستثمارات \\
\hline 0.84 & 3.249 & 0.46 & 0.02 & $\begin{array}{r}\hat{Y}_{t}=2.92+0.03 X_{t} \\
(0.68)\end{array}$ & الخاصة & $\begin{array}{c}\text { (مليار جنيه) } \\
\text { (لزراعية }\end{array}$ \\
\hline 1.03 & 5.725 & 0.43 & 0.02 & $\begin{array}{r}\hat{Y}_{t}=5.02+0.06 X_{t} \\
(0.65)\end{array}$ & الأجمالى & \\
\hline 8.44 & 192.930 & 205.52 & 0.91 & $\begin{array}{r}\hat{Y}_{\mathrm{t}}=-2.54+16.29 \mathrm{X}_{\mathrm{t}} \\
(14.33)^{* *}\end{array}$ & العام & الناتج المحلى \\
\hline 9.09 & 368.077 & 82.55 & 0.8 & $\begin{array}{r}\hat{Y}_{\mathrm{t}}=-33.23+33.44 \mathrm{X}_{\mathrm{t}} \\
(9.08)^{* *}\end{array}$ & الخاص & (مليار جنيه) \\
\hline 8.86 & 561.007 & 109.45 & 0.84 & $\begin{array}{r}\hat{Y}_{\mathrm{t}}=-35.77+49.73 \mathrm{X}_{\mathrm{t}} \\
(10.46)^{* *}\end{array}$ & الأجمالى & \\
\hline-5.46 & 0.083 & 5.55 & 0.21 & $\begin{array}{r}\hat{Y}_{t}=0.14-0.004 X_{t} \\
(-2.35)^{*}\end{array}$ & العام & الناتج الزراعى \\
\hline 6.79 & 72.814 & 93.86 & 0.82 & $\begin{array}{r}\hat{\mathrm{Y}}_{\mathrm{t}}=13.45+ \\
\left(9.95 \mathrm{X}_{\mathrm{t}}\right. \\
(9.69)^{* * *}\end{array}$ & الخاص & (مليار جنيه) \\
\hline 6.78 & 72.897 & 93.1 & 0.81 & $\begin{array}{r}\hat{Y}_{\mathrm{t}}=13.59+4.94 \mathrm{X}_{\mathrm{t}} \\
(9.65)^{* *}\end{array}$ & الأجمالى & \\
\hline
\end{tabular}

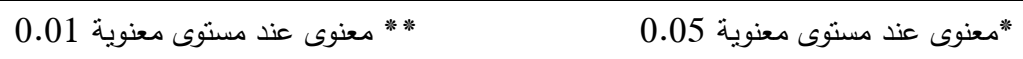

المصدر : حسبت من بيانات الجدول رقم (1) .

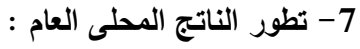

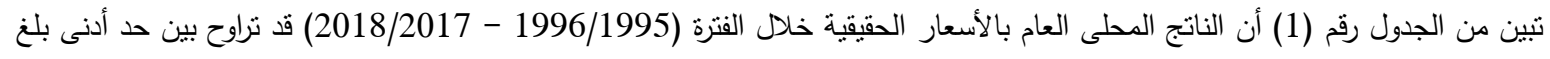

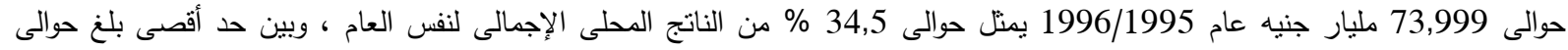

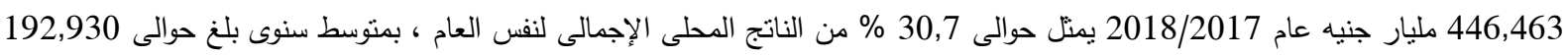

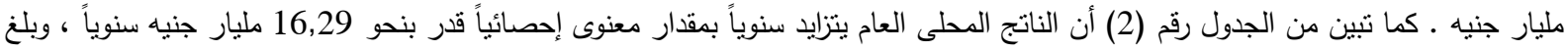

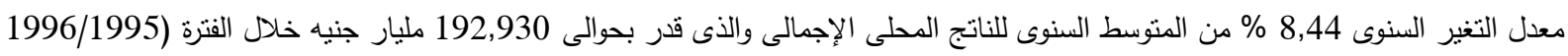

. (2018/2017 -

8 - تطور الناتج المحلى الخاص :

تبين من الجدول رقم (1) أن الناتج المحلى الخاص بالأسعار الحقيقية خلال الفترة (1996/1995- 2018/2017) قد تزاوح بين حد أدنى بلغ

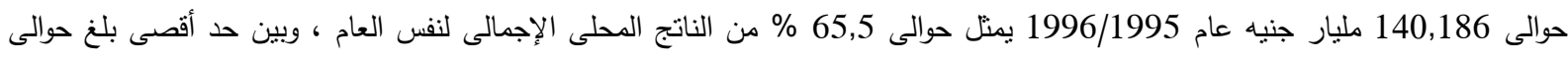

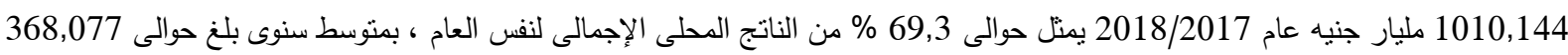

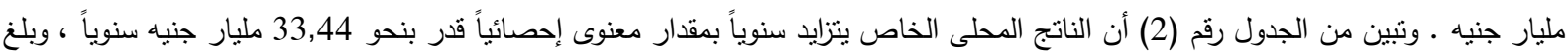
معدل التغير السنوى 9,09 \% من المتوسط السنوى للناتج المحلى الخاص والذى قدر بحوالى 368,077 مليار جنيه خلال الفنرة (1996/1995 . $(2018 / 2017$ 9- تطور الناتج المحلى الإجمالى : وبدراسة تطور الناتج المحلى الإجمالى بالأسعار الحقيقية خلال الفترة (1996/1995 - 2018/2017) تبين من الجدول رقم (1) أن النانج

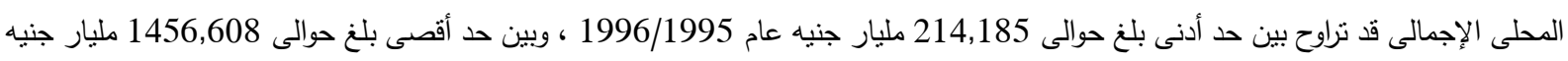

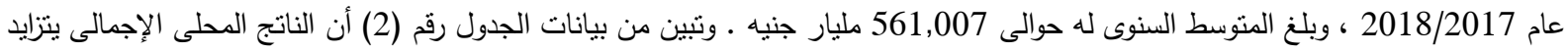

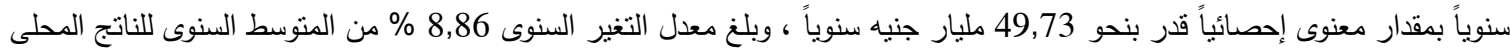
الإجمالى والذى قدر بحوالى 561,007 مليار جنيه خلال الفترة (1996/1995- 2018/2017). 


\section{0- ت تطور الناتج الزراعى العام :}

تبين من الجدول رقم (1) أن الناتج الزراعى العام بالأسعار الحقيقة خلال الفترة (1996/1995- 2018/2017) قد تراوح بين حد أدنى بلغ حوالى 0,007 مليار جنيه عام 2006/2005 يمثل حوالى 0,02 \% من الناتج الزراعى الإجمالى لنفس العام ، وبين حد أقصى بلغ حوالى

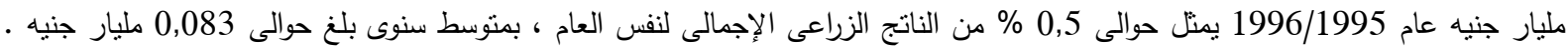

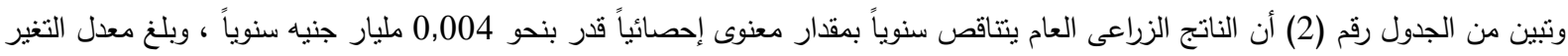
السنوى - 5,46 \% من المتوسط السنوى للناتج الزراعى الإجمالى والذى قدر بحوالى 0,083 مليار جنبه خلال الفنتر (1996/1995 -

. (2018/2017

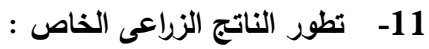

تبين من الجدول رقم (1) أن الناتج الزراعى الخاص بالأسعار الحقيقة خلال الفترة (1996/1995- 2018/2017) قد تزاوح بين حد أدنى بلغ حوالى 36,772 مليار جنيه عام 1996/1995 يمثل حوالى 99,5 \% من الناتج الزراعى الإجمالى لنفس العام ، وبين حد أقصى بلغ حوالى القالى 167,287 مليار جنيه عام 2018/2017 يمثل حوالى 99,9 \% من الناتج الزراعى الإجمالى لنفس العام ، وبمتوسط سنوى بلغ حوالى الإلى

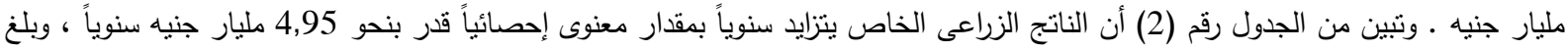

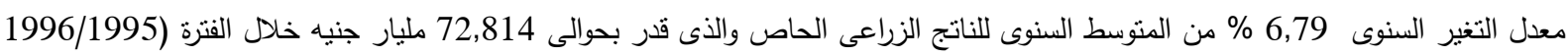
· (2018/2017 -

12- النطور الناتج الزراعى الإجمالى :

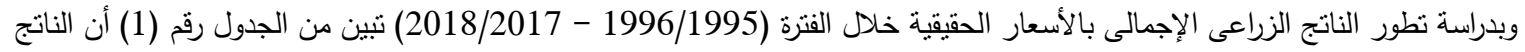

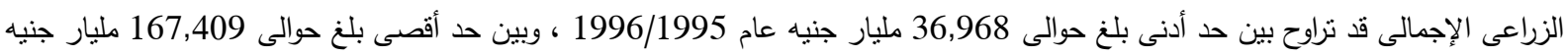

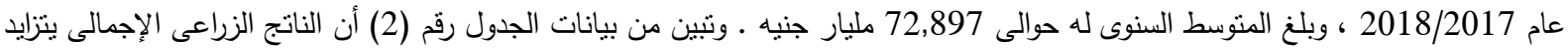

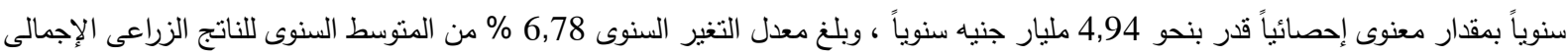

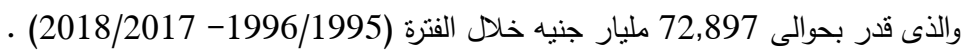

ثانياً : تقبير كفاءة الأستثمارات الزراعية : وذلك من خلال تقدير بعض المؤثرات الأقتصادية (السعدى 2009 ، عبد الحميد 2010 ، جرجس 2014 ، عبد الحميد 2014) ومنها :

: Investment Rate معدل الأستثمار

وهو يوضح حجم الأستثمار اللازم لإنتاج وحدة واحدة من الناتج المحلى ، ويتم حسابه من المعادلة التالية :

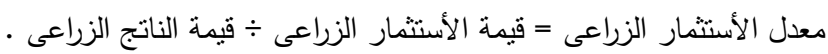

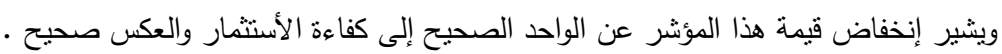

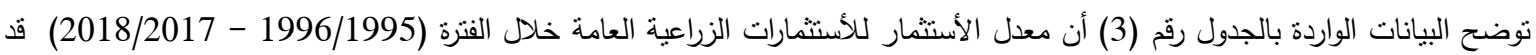

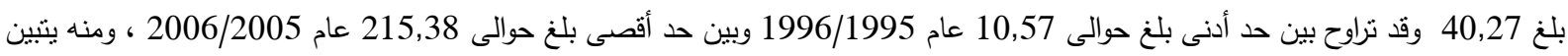

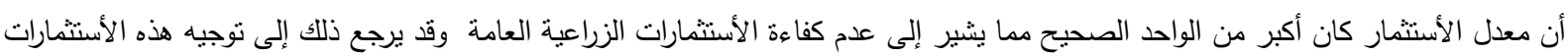

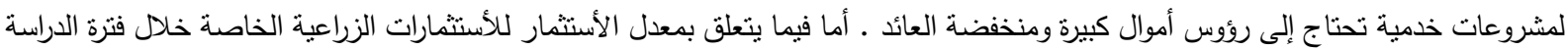

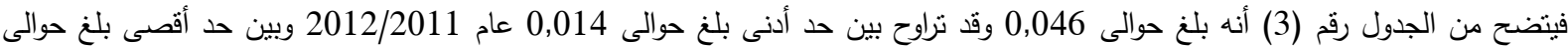

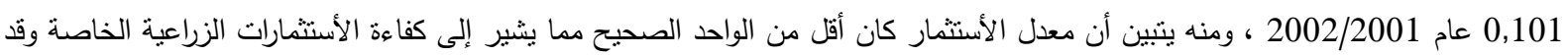

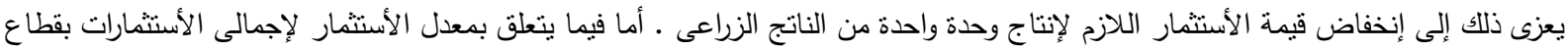

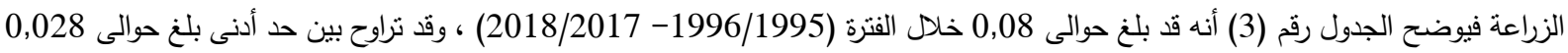
عام 2012/2011 وبين حد أقصى بلغ حوالى 0,179 عام 1998/1997 ، ومنه ينتين أن معدل الأستثمار كان أقل من الواحد الصحيح مما يشير

إلى كفاءة الأستثمارات الزراعية بصورة عامة خلال فترة الدراسة .

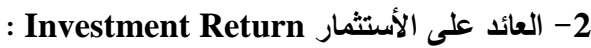

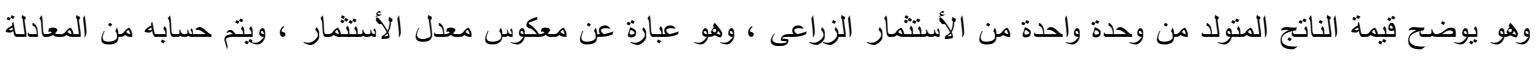

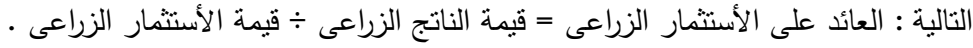

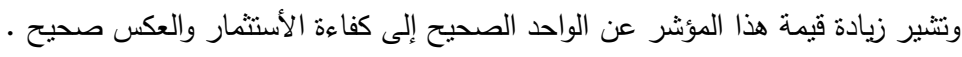


جدول 3. تطور مؤشرات كفاءة الأستمار الزراعى فى جمهورية مصر العربية خلال الفترة (1996/1995 - 2018/2017)

\begin{tabular}{|c|c|c|c|c|c|c|c|c|c|c|c|c|c|}
\hline \multicolumn{3}{|c|}{ للأستثمارات الزراعية } & \multirow{2}{*}{ معامل التكثيف الرأسمالى لإجمالى الأستثمارات } & \multicolumn{3}{|c|}{ للأستثمارات الزراعتثمار } & \multicolumn{3}{|c|}{ للأستثمارات على الزأستثمارة } & \multicolumn{3}{|c|}{ للأستثمارات الزراعية } & \multirow[t]{2}{*}{ السنـه } \\
\hline الإجمالية & الخاصة & العامة & & الإجمالية & الخاصة & العامة & الإجمالية & الخاصة & العامة & الإجمالية & الخاصة & العامة & \\
\hline 0.473 & 0.444 & 22.88 & 0.945 & - & - & - & 8.24 & 15.25 & 0.095 & 0.121 & 0.066 & 10.57 & $1995 / 1996$ \\
\hline 0.447 & 0.377 & 27.39 & 0.994 & 5.48 & 16.89 & -0.109 & 8.07 & 15.31 & 0.076 & 0.124 & 0.065 & 13.13 & $1996 / 1997$ \\
\hline 0.777 & 0.740 & 46.05 & 1.478 & 0.78 & 2.21 & 0.000 & 5.60 & 11.94 & 0.045 & 0.179 & 0.084 & 22.31 & $1997 / 1998$ \\
\hline 0.759 & 0.599 & 49.68 & 1.482 & 17.02 & 4.03 & -0.007 & 5.81 & 10.77 & 0.052 & 0.172 & 0.093 & 19.38 & 1998/1999 \\
\hline 0.754 & 0.663 & 44.29 & 1.397 & -10.03 & 9.59 & -0.009 & 6.50 & 10.68 & 0.065 & 0.154 & 0.094 & 15.34 & $1999 / 2000$ \\
\hline 0.779 & 0.688 & 44.22 & 1.381 & -22.29 & 4.56 & -0.010 & 6.72 & 10.33 & 0.075 & 0.149 & 0.097 & 13.37 & $2000 / 2001$ \\
\hline 0.863 & 0.740 & 233.32 & 1.638 & 2.13 & 5.50 & -0.209 & 6.08 & 9.89 & 0.015 & 0.164 & 0.101 & 68.44 & $2001 / 2002$ \\
\hline 0.575 & 0.366 & 263.18 & 0.940 & -0.61 & -0.75 & 0.009 & 9.97 & 20.03 & 0.016 & 0.100 & 0.050 & 63.14 & $2002 / 2003$ \\
\hline 0.626 & 0.443 & 277.73 & 0.900 & -4.74 & -4.37 & 0.145 & 9.16 & 17.30 & 0.015 & 0.109 & 0.058 & 68.44 & $2003 / 2004$ \\
\hline 0.518 & 0.380 & 227.50 & 0.790 & 2.33 & 10.25 & 0.005 & 10.15 & 17.70 & 0.017 & 0.099 & 0.056 & 58.70 & $2004 / 2005$ \\
\hline 0.494 & 0.339 & 1005.89 & 0.718 & 9.59 & -4.87 & 0.064 & 10.16 & 15.59 & 0.005 & 0.098 & 0.064 & 215.38 & $2005 / 2006$ \\
\hline 0.356 & 0.240 & 606.53 & 0.612 & -20.98 & -89.54 & -0.010 & 12.83 & 18.65 & 0.008 & 0.078 & 0.054 & 128.11 & $2006 / 2007$ \\
\hline 0.306 & 0.186 & 644.25 & 0.556 & -2.62 & -2.16 & -0.001 & 14.01 & 21.65 & 0.007 & 0.071 & 0.046 & 135.67 & $2007 / 2008$ \\
\hline 0.255 & 0.196 & 426.32 & 0.501 & -25.82 & -26.55 & -0.131 & 19.74 & 32.88 & 0.009 & 0.051 & 0.030 & 114.29 & $2008 / 2009$ \\
\hline 0.208 & 0.137 & 419.70 & 0.472 & -30.17 & -32.53 & -0.061 & 23.87 & 41.64 & 0.010 & 0.042 & 0.024 & 102.79 & $2009 / 2010$ \\
\hline 0.206 & 0.108 & 561.72 & 0.442 & -47.50 & -31.20 & 0.015 & 27.83 & 53.44 & 0.010 & 0.036 & 0.019 & 99.27 & $2010 / 2011$ \\
\hline 0.198 & 0.103 & 139.59 & 0.368 & 2.25 & 3.94 & -0.145 & 35.15 & 69.93 & 0.047 & 0.028 & 0.014 & 21.21 & $2011 / 2012$ \\
\hline 0.318 & 0.220 & 145.67 & 0.537 & 6.19 & 6.73 & 0.072 & 25.02 & 38.57 & 0.049 & 0.040 & 0.026 & 20.34 & $2012 / 2013$ \\
\hline 0.401 & 0.282 & 176.18 & 0.732 & 9.02 & 14.30 & 0.020 & 20.77 & 32.26 & 0.041 & 0.048 & 0.031 & 24.39 & $2013 / 2014$ \\
\hline 0.357 & 0.259 & 148.22 & 0.789 & 20.69 & 48.99 & 0.029 & 20.76 & 33.93 & 0.038 & 0.048 & 0.029 & 26.07 & $2014 / 2015$ \\
\hline 0.348 & 0.309 & 97.72 & 0.905 & 12.59 & 10.82 & -0.071 & 19.59 & 28.35 & 0.047 & 0.051 & 0.035 & 21.44 & $2015 / 2016$ \\
\hline 0.364 & 0.472 & 59.02 & 1.213 & 10.37 & 8.01 & -0.019 & 18.23 & 23.37 & 0.060 & 0.055 & 0.043 & 16.80 & $2016 / 2017$ \\
\hline 0.584 & 0.385 & 251.21 & 2.889 & 2.81 & -30.31 & 0.002 & 10.29 & 31.11 & 0.011 & 0.097 & 0.032 & 88.97 & $2017 / 2018$ \\
\hline 0.434 & 0.326 & 157.22 & 0.87 & -2.89 & -3.47 & -0.019 & 12.53 & 21.73 & 0.025 & 0.08 & 0.05 & 40.27 & المتوسط \\
\hline 0.198 & 0.103 & 22.88 & 0.368 & -47.50 & -89.54 & -0.209 & 5.60 & 9.89 & 0.005 & 0.028 & 0.014 & 10.57 & الحد الأدنى \\
\hline 0.863 & 0.740 & 1005.89 & 2.889 & 20.69 & 48.99 & 0.145 & 35.15 & 69.93 & 0.095 & 0.179 & 0.101 & 215.38 & الد الأقصى \\
\hline
\end{tabular}

المصدر : جمعت وحسبت من 10. بيانات الجدول رقم (1) .

2- الجهاز المركزى للتعبئة العامة والأحصاء، الكتاب الأحصائى السنوى ، أعداد مختلفة . 
وتوضح البيانات الواردة بالجدول رقم (3) أن العائد على الأستثمارات الزراعية العامة خلال الفترة (1996/1995-

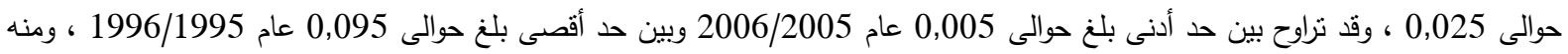

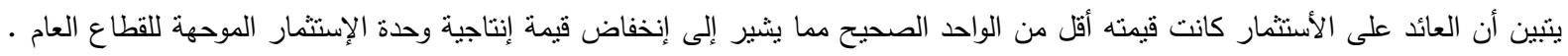

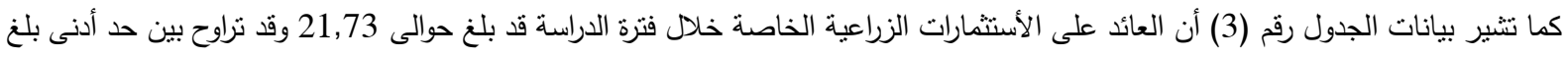

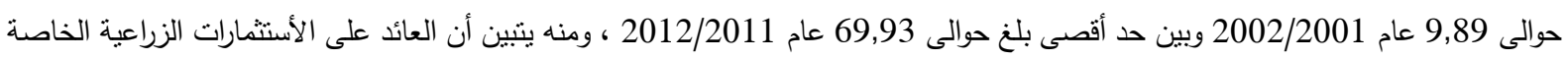

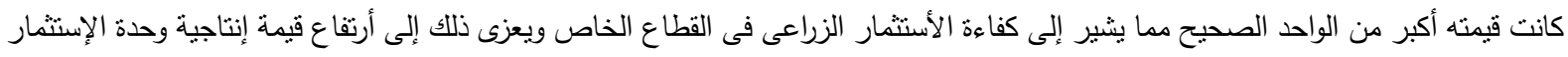

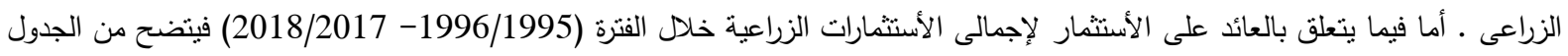

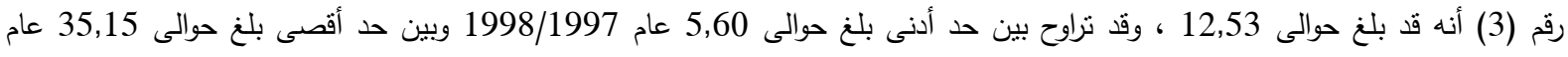

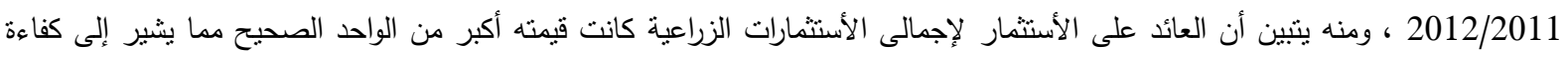

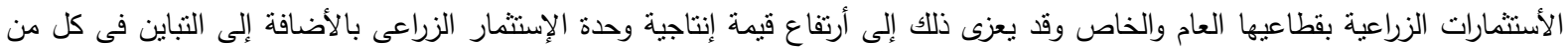

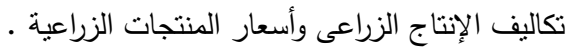

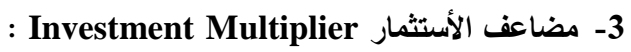

وهو يوضح مقدار التغير فى قيمة الناتج المتولد من تغير الأستثمار بوحدة واحدة ، ويتم حسابه من المعادلة النالية :

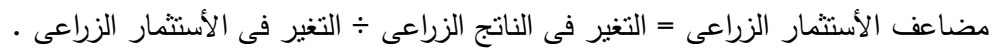

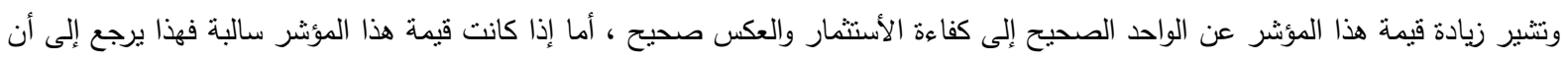

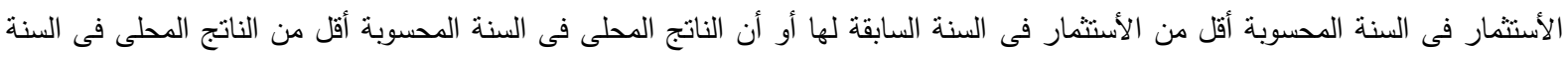

السابقة لها.

ويتضح من بيانات الجدول رقم (3) أن قيمة مضاعف الأستثمار الموجه للقطاع العام خلال الفترة (1996/1995-

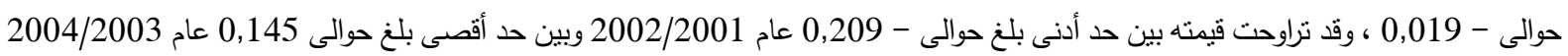

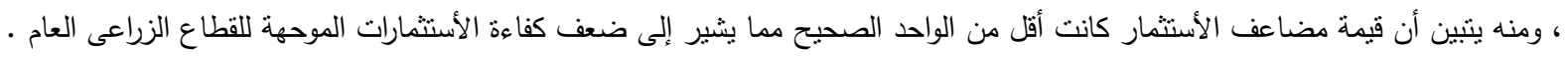

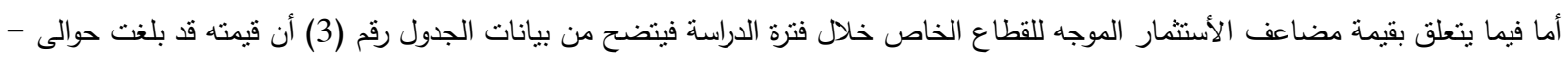

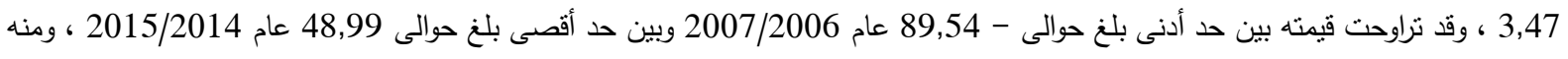

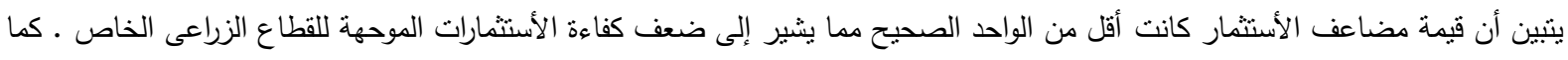

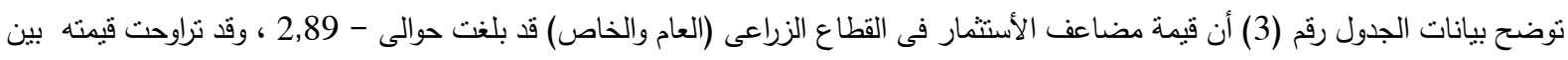

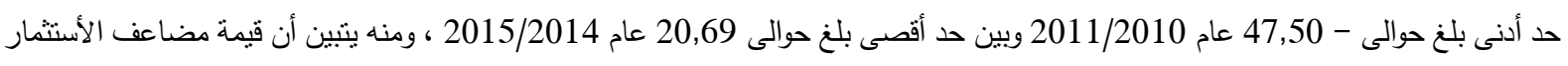

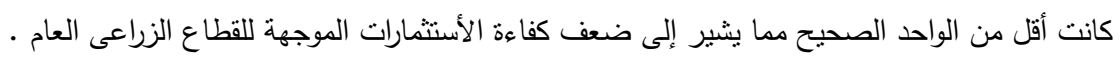

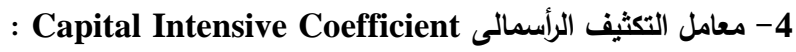
يشير معامل التكثيف الرأسمالى أومعامل التوظف إلى النسبة بين الأستثار الزراعى وعدد العمال فى القطاع الزراعى ، ويتم حسابه من المعادلة

معامل التوظف = إجمالى الأستثمار الزراعى ؟ عدد العمال الزراعيين . ويشير إنخفاض قيمة هذا المؤشر عن الواحد الصحيح إلى كثافة أستخدام العامل البشرى فى قطاع الزئل الزراعة بينما تثشير زيادة قيمة هذا المؤشر عن

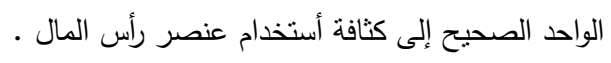

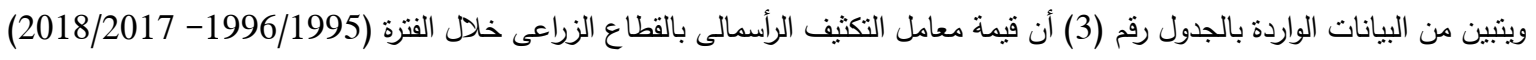

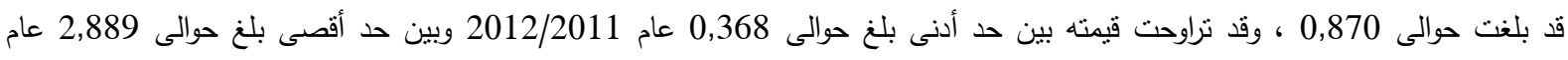

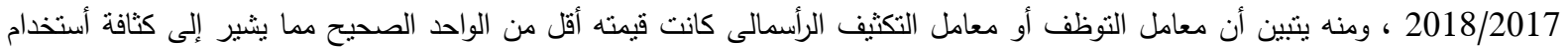

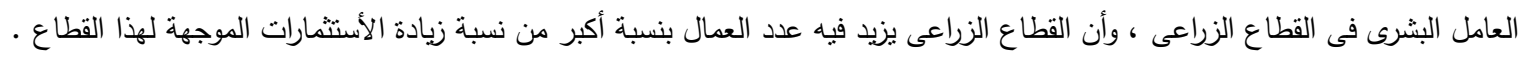

: Investment Factor Domesticating معاعل الزعل ويوضح هذا المؤشر مدى مساهمة قطاع الزراعة فى الناتج المحلى الإجمالى وفقاً لحجم الأستثمارات فى هذا القطاع ، ويتم حسابه من المعادلة التالية : معامل التوطن = نسبة الأستثمار الزراعى من الأستثمار الكلى ٪ نسبة الناتج المحلى الزراعى من الناتج المحلى الإجمالى .

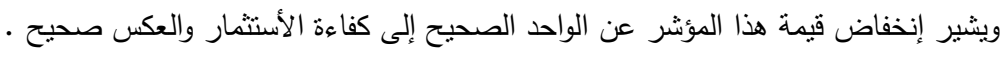

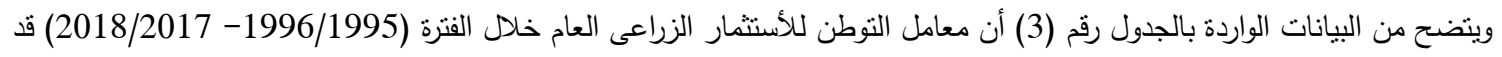


بلغ حوالى 157,22 ، وقد تراوحت قيمته بين حد أدنى بلغ حوالى 22,88 عام 1996/1995 وبين حد أقصى بلغ حوالى 1005,89 عام 2006/2005 ، مما يعكس ضعف كفاءة الأستثمارات الزراعية فى هذا القطاع ـ أما فيما يتعلق بمعامل التوطن للأستثمار الزراعى الخاص خلال

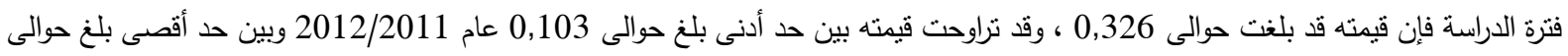

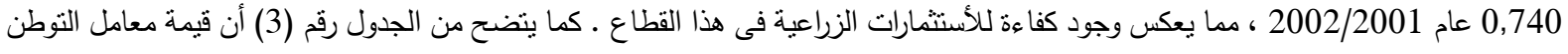

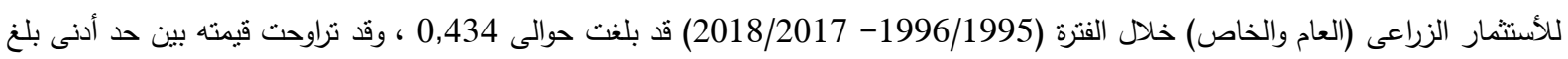

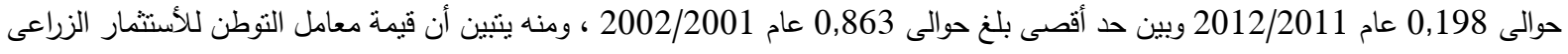
(العام والخاص) كانت أقل من الواحد الصحيح مما يدل على كفاءة الأستثمارات الزراعية أى أنها لم تتجاوز قيمة الناتج المحلى الزراعى المتولد منها

ثالثاً : العلاقة بين الأستثمار الزراعى والناتج الزراعى :

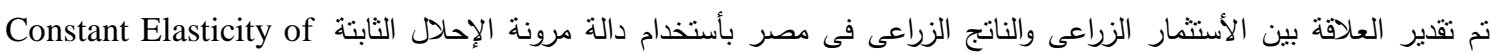
Substitution (CES)

$\ln Q_{t}=\ln \gamma+d c \ln K_{t}+d(1-c) \ln L_{t}-0.5 p d(1-c)\left[\ln K_{t}-\ln L_{t}\right]^{2}+U_{t}$

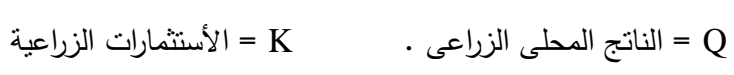

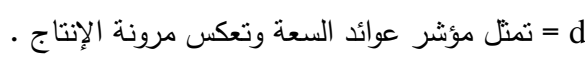

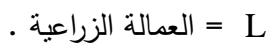

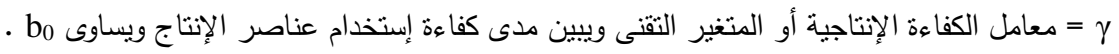

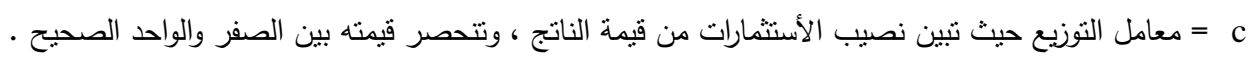

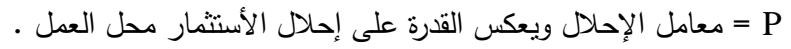

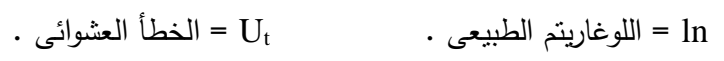

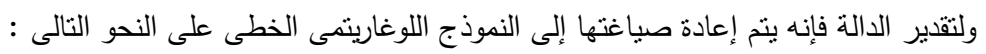

$\ln Q=b_{0}+b_{1} \ln K+b_{2} \ln L+b_{3}[\ln K-\ln L]^{2}+U_{t}$

والجدول رقم (4) يبين دالة مرونة الإحلال الثابتة (CES) ومنه يتبن أن مرونة الإنتاج بالنسبة للعمل أعلى من مرونة الإنتاج بالنسبة

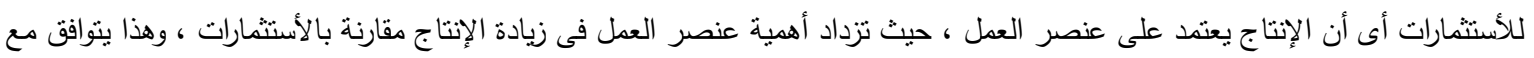

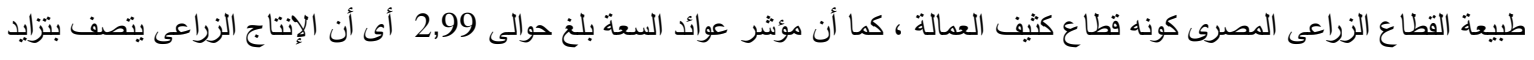

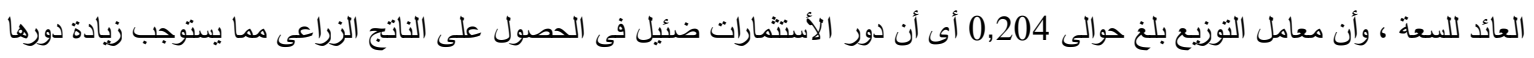

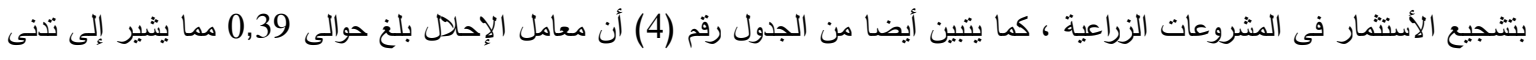

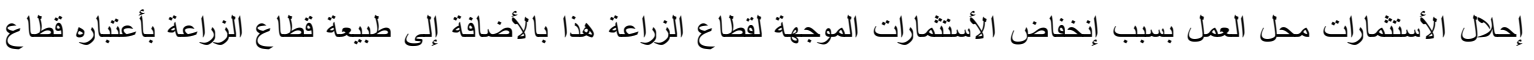
كثيف العمالة . جدول 4. تقدير العلاقة بين الأستثمار الزراعى والناتج الزراعى فى مصر بأستخدام دالة مرونة الإحلال الثابتة خلال الفترة (1996/1995-

(2018/2017

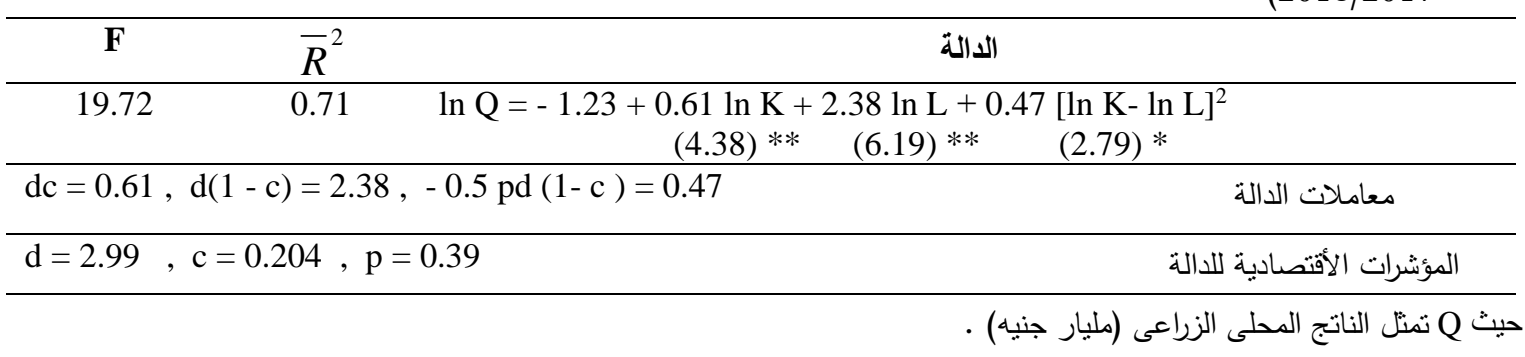

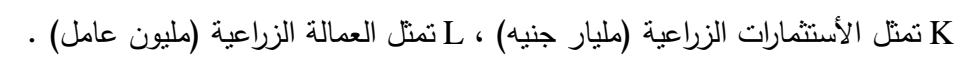

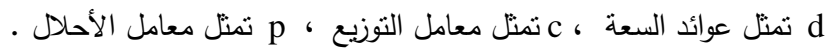

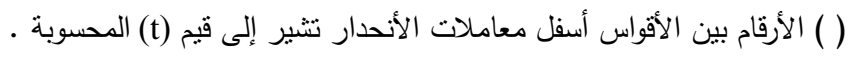

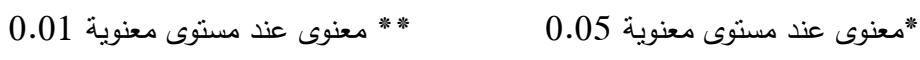

المصدر : جمعت وحسبت من : الجدول رقم (1) بالملحق . رابعاً : العوامل الموئثرة على الأستثمار الززاعى : 


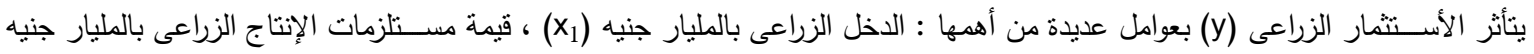

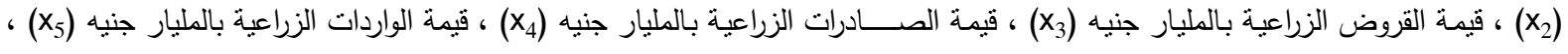

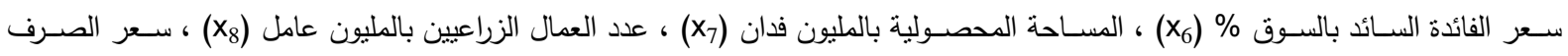

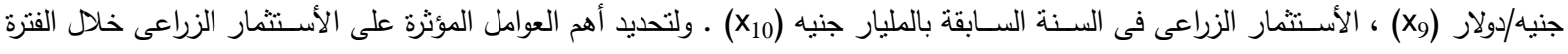

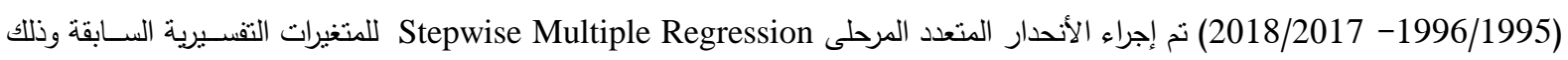

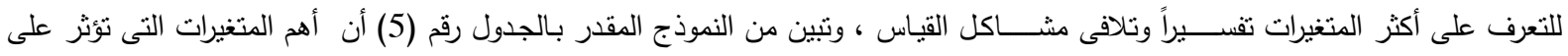

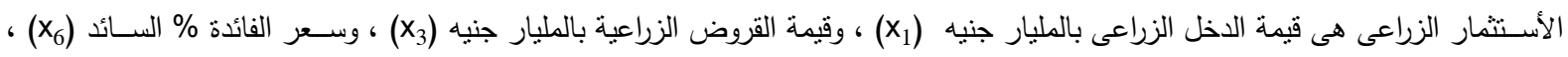

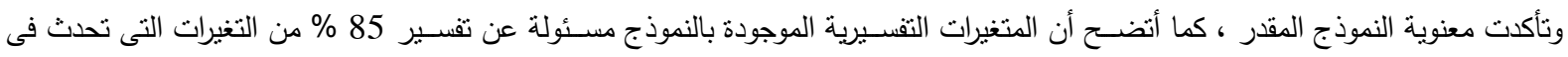

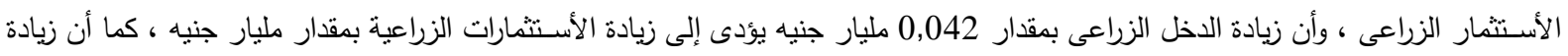

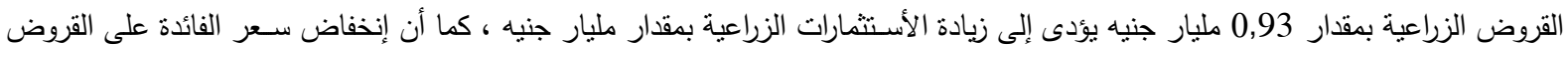

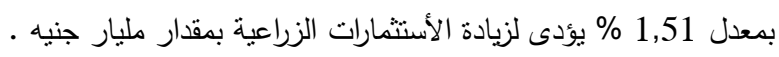

جدول 5. النقدير الإحصائى للعلاقة الدالية بين الأستثمار الزراعى والعوامل المؤثرة عليه فى جمهورية مصر العربية خلال الفترة (1996/1995(2018/2017

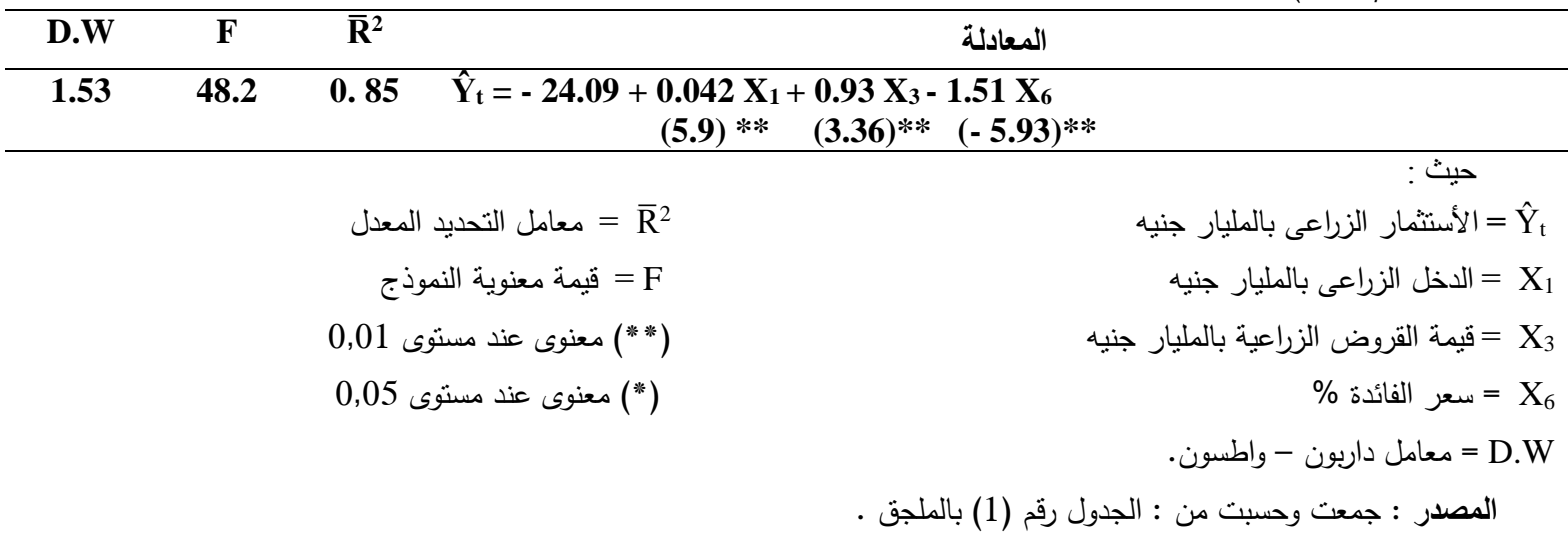

خامساً : قياس أثر الأستثمارات الزراعية على معدل نمو القطاع الزراعى :

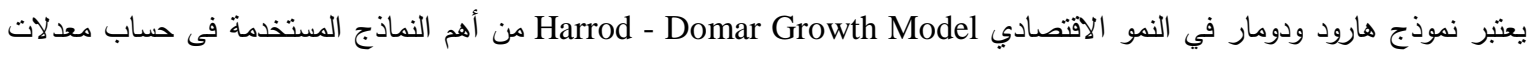

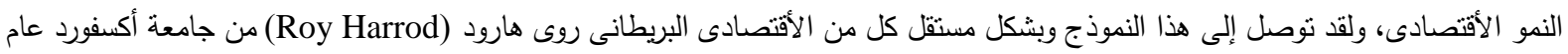

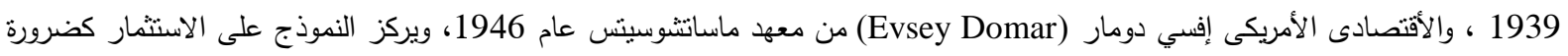

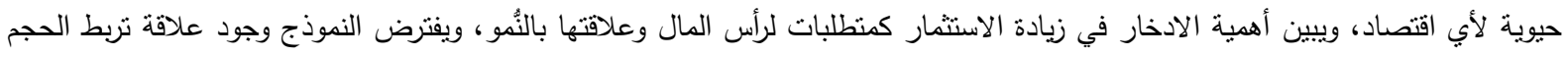

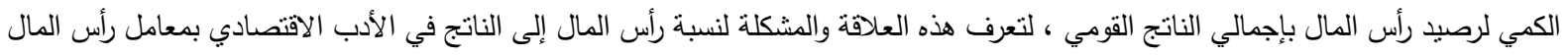

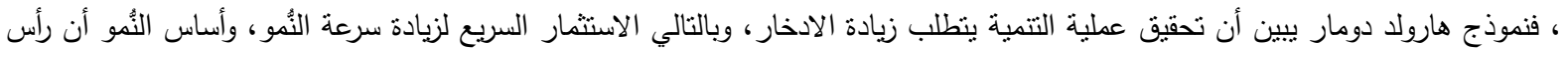

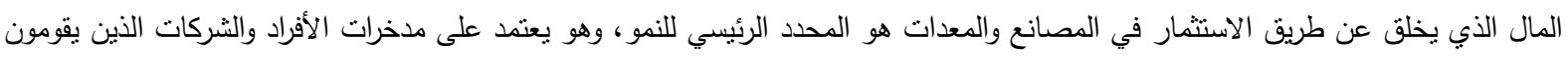

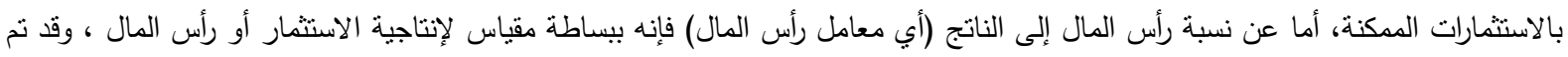

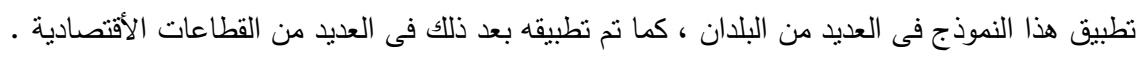

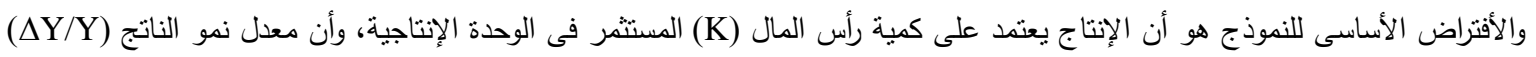

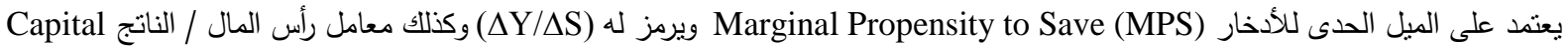

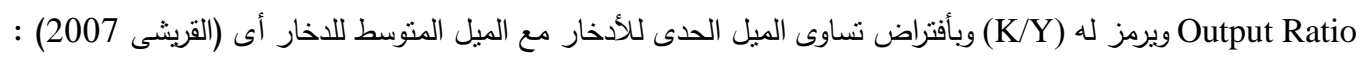
$\Delta \mathbf{Y} / \Delta \mathbf{S}=\mathbf{S} / \mathbf{Y}=\mathbf{S}$

$$
\text { حيث أن (S) هى معدل الأدخار }
$$

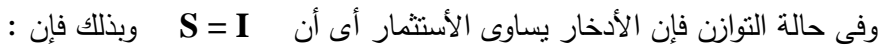
$\mathbf{i}=\mathbf{I} / \mathbf{Y}$

حيث (i) هو معدل الأستثمار ، وأن الأستثمار (I) هو التغيير الذى يحدث فى رأس المال أو هو التراكم الرأسمالى الحادث أى أن : $\mathbf{I}=\Delta \mathbf{K}$ 
والمعامل الحدى لرأس المال / الناتج بساوى (K) أى ان :

$\Delta \mathbf{K} / \Delta \mathbf{Y}=\mathbf{K}=\mathbf{I} / \Delta \mathbf{Y}$

ومن المعادلة رقم (4) نحصل على :

$\Delta \mathbf{K} / \Delta \mathbf{Y}=\mathbf{I} / \Delta \mathbf{Y}$

$\Delta \mathbf{Y} / \mathbf{Y}=(\mathbf{1} / \mathbf{Y}) / \mathbf{K}$

وبقسمة طرفى المعادلة (5) على Y نحصل على : (6)

وعليه فإن معدل النمو فى الناتج بساوى معدل الأستثمار أو معدل الأدخار مقسوماً على المعامل الحدى لرأس المال / الناتج .

$$
\mathbf{G}=\mathbf{I} / \mathbf{K}
$$

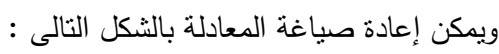

$$
\text { حيث أن : معدل : }
$$

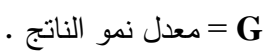

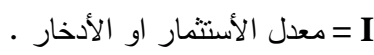

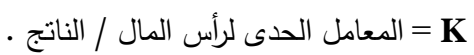

وبنطبيق هذا النموذج على القطاع الزراعى المصرى لقياس أثر الأستثارات الزراعية المنفذة على معدل نمو القطاع الزراعى خلال الفنترة

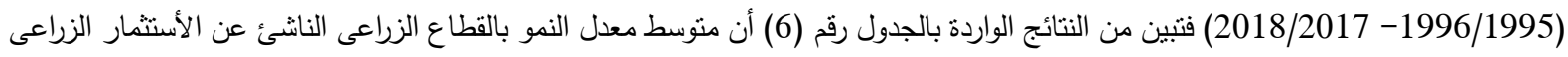

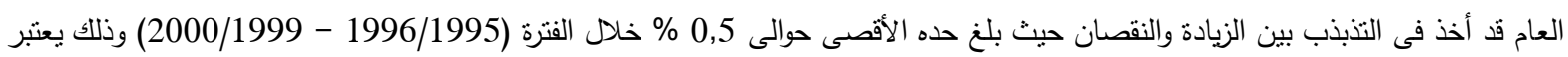

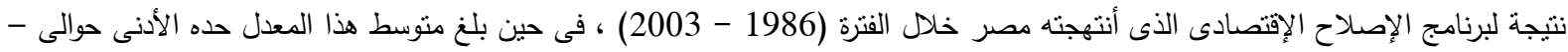

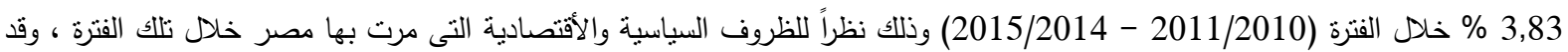

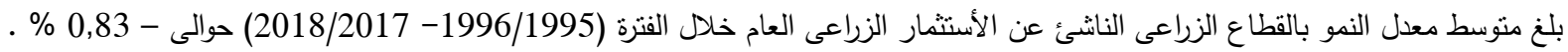

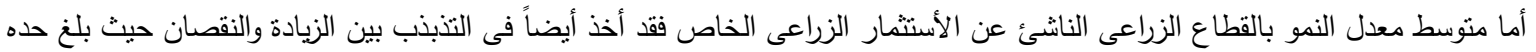
الأقصى حوالى 2,01 \% خلال الفترة (2001/2000 - 2005/2004) ، فى حين بلغ متوسط هذا المعدل حده الأدنى حوالى - 0,18 \% خلاعل الفترة (1996/1995 - 2000/1999) ، وقد بلغ متوسط معدل النمو بالقطاع الزراعى النانشئ عن الأستثمار الزراعى الخاص حوالى

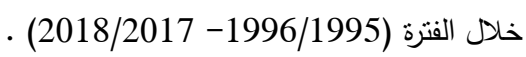
أما متوسط معدل النمو بالقطاع الزراعى الناثئ عن إجمالى الأستثمار الزراعى (العام ، الخاص) فقد بلغ حده الأدنى حوالى - 0,47 \% خلال الفترة (2001/2000 - 2005/2004) ، فى حين بلغ متوسط هذا المعدل حده الأقصى حوالى 1,74 \% خلاعل الفئ الفترة (2016/2015 2018/2017) وهى الفترة التى بدء فيها تتفيذ مشروع أستصلاح المليون ونصف فدان وإقامة العديد من التجمعات الزراعية بمحافظات شمال وجنوب

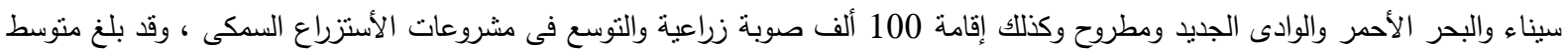

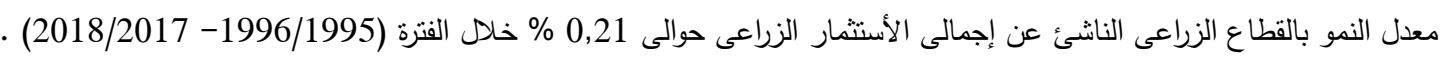

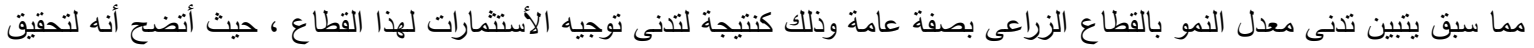

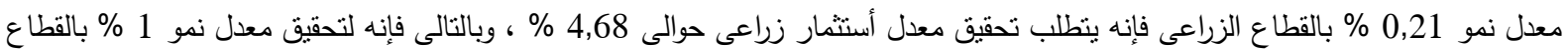

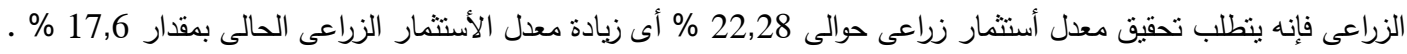


جدول 6. تطور معدل الأستثمار والمعدل الحدى لرأس المال ومعدل النمو فى القطاع الزراعى المصرى خلال الفترة (1996/1995(2018/2017

\begin{tabular}{|c|c|c|c|c|c|c|c|c|c|}
\hline \multicolumn{3}{|c|}{ معدل النمو فى القطاع الزراعى } & \multicolumn{3}{|c|}{ المعدل الحدى لرأس المال } & \multicolumn{3}{|c|}{ معدل الأستثمار الزراعى } & \multirow[t]{2}{*}{ السنة } \\
\hline الإجمالى & 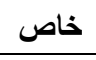 & 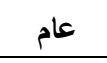 & الإجمالى & 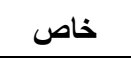 & عام & الإجمالى & 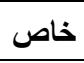 & عام & \\
\hline- & - & - & - & - & - & 10.68 & 5.75 & 4.94 & $1995 / 1996$ \\
\hline-2.45 & -0.86 & 2.31 & -4.15 & -6.24 & 2.09 & 10.18 & 5.34 & 4.84 & $1996 / 1997$ \\
\hline-0.06 & -0.08 & -0.05 & -244.20 & -83.04 & -161.16 & 15.12 & 7.05 & 8.06 & $1997 / 1998$ \\
\hline 5.76 & 0.27 & -0.26 & 2.54 & 28.85 & -26.30 & 14.65 & 7.87 & 6.78 & $1998 / 1999$ \\
\hline 0.06 & -0.05 & 0.01 & 233.99 & -185.73 & 419.72 & 13.97 & 8.46 & 5.51 & $1999 / 2000$ \\
\hline 0.83 & -0.18 & 0.50 & -2.95 & -61.54 & 58.59 & 12.75 & 6.79 & 5.91 & المتوسط \\
\hline-1.71 & 0.93 & -0.27 & -7.68 & 9.15 & -16.83 & 13.11 & 8.49 & 4.62 & $2000 / 2001$ \\
\hline 0.81 & 1.26 & 0.52 & 16.65 & 6.59 & 10.06 & 13.48 & 8.29 & 5.19 & $2001 / 2002$ \\
\hline-0.10 & -0.07 & -0.25 & -72.22 & -57.16 & -15.07 & 7.53 & 3.74 & 3.79 & $2002 / 2003$ \\
\hline-1.34 & 7.94 & -0.58 & -4.93 & 0.44 & -5.37 & 6.62 & 3.50 & 3.12 & $2003 / 2004$ \\
\hline-0.01 & -0.01 & 0.00 & -798.33 & -300.47 & -497.86 & 5.14 & 2.94 & 2.20 & $2004 / 2005$ \\
\hline-0.47 & 2.01 & -0.12 & -173.30 & -68.29 & -105.01 & 8.53 & 4.86 & 3.62 & المتوسط \\
\hline 0.10 & 1.08 & 0.04 & 46.91 & 2.72 & 44.19 & 4.52 & 2.95 & 1.57 & $2005 / 2006$ \\
\hline-0.53 & -0.91 & -0.27 & -6.95 & -2.78 & -4.18 & 3.66 & 2.52 & 1.14 & $2006 / 2007$ \\
\hline-0.26 & -0.19 & -0.82 & -11.30 & -10.06 & -1.25 & 2.89 & 1.87 & 1.02 & $2007 / 2008$ \\
\hline-0.33 & -0.18 & 2.05 & -7.65 & -8.14 & 0.49 & 2.51 & 1.50 & 1.00 & $2008 / 2009$ \\
\hline-0.17 & -0.12 & -0.32 & -12.71 & -9.89 & -2.82 & 2.12 & 1.22 & 0.91 & $2009 / 2010$ \\
\hline-0.24 & -0.06 & 0.13 & 1.66 & -5.63 & 7.29 & 3.03 & 1.91 & 1.11 & المتوسط \\
\hline-0.80 & -0.42 & -20.06 & -2.11 & -2.07 & -0.04 & 1.69 & 0.88 & 0.81 & $2010 / 2011$ \\
\hline-0.16 & -0.14 & -0.19 & -7.71 & -4.48 & -3.23 & 1.23 & 0.62 & 0.61 & $2011 / 2012$ \\
\hline 0.15 & 0.10 & 0.75 & 12.11 & 11.27 & 0.84 & 1.78 & 1.15 & 0.63 & $2012 / 2013$ \\
\hline 0.29 & 0.29 & 0.27 & 7.72 & 4.86 & 2.86 & 2.20 & 1.42 & 0.79 & $2013 / 2014$ \\
\hline 0.12 & 0.17 & 0.08 & 21.49 & 9.42 & 12.07 & 2.56 & 1.57 & 1.00 & $2014 / 2015$ \\
\hline-0.08 & 0.00 & -3.83 & 6.30 & 3.80 & 2.50 & 1.84 & 1.07 & 0.75 & المتوسط \\
\hline 0.79 & 0.41 & -0.73 & 3.32 & 4.43 & -1.11 & 2.63 & 1.82 & 0.81 & $2015 / 2016$ \\
\hline 4.61 & 0.81 & -0.30 & 0.52 & 2.30 & -1.78 & 2.40 & 1.87 & 0.53 & $2016 / 2017$ \\
\hline-0.18 & 0.39 & -0.11 & -27.13 & 4.30 & -31.43 & 5.00 & 1.65 & 3.35 & $2017 / 2018$ \\
\hline 1.74 & 0.54 & -0.38 & -7.76 & 3.67 & -11.44 & 3.16 & 1.78 & 1.13 & المتوسط \\
\hline 0.21 & 0.48 & -0.83 & -39.17 & -26.62 & -12.55 & 4.68 & 2.69 & 1.90 & المتوسط العام \\
\hline
\end{tabular}

معدل النمو فى القطاع الزراعى = معدل الأستتمار الزراعى ٪ المعدل الحدى لرأس المال .

المصدر : جمعت وحسبت من : الجدول رقم (1) بالملجق .

(الملخص : (1)

يتطلب قيام القطاع الزراعى بدوره فى عملية التتمية الأقتصادية ضرورة توفر قدر مناسب من الأستمارات ، حيث تعتبر الإستثمارات من أهم

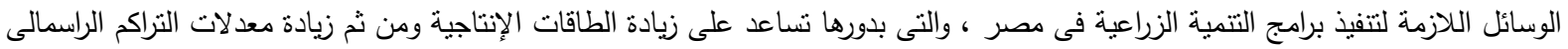

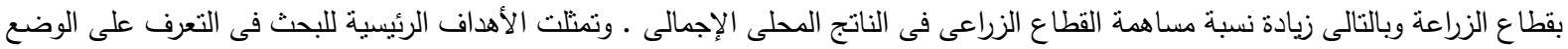

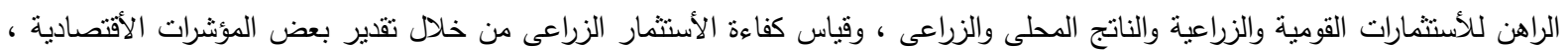
وتقدير العلاقة بين الأستثمار الزراعى والناتج الزراعى ، والتعرف على أهم العوامل المؤثرة على الإستثمار الزراعى ، وقياس أثر الأستثمارات الزراعية

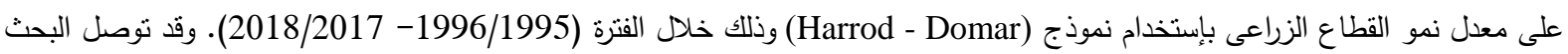

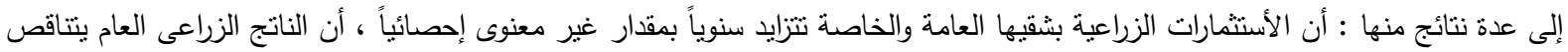
سنوياً بمقدار معنوى إحصائياً قدر بنحو 0,004 مليار جنيه سنوياً ، فى حين ينزايد الناتج الزراعى الخاص سنوياً بمقدار معنوى إحصائياً قدر بنحو

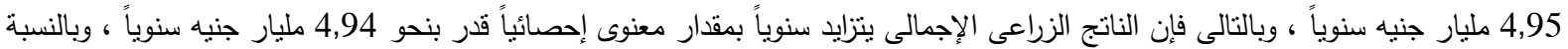

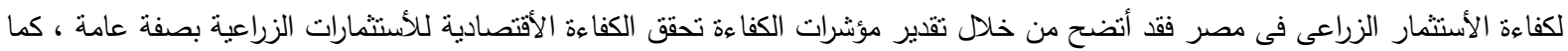
أنضح تفوق القطاع الخاص على القطاع العام فى تحقيق الكفاءة الأقتصادية للأستثمارات ، وتنين من تقدير العلاقة بين الأستثمار الزراعى والناتج

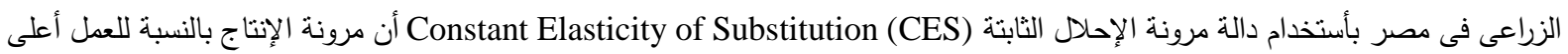


من مرونة الإنتاج بالنسبة للأستثمارات أى أن الإنتاج يعتمد على عنصر العمل ، حيث نزداد أهمية عنصر العمل فى زيادة الإنتاج مقارنة بالأستثمارات ، وهذا ينوافق مع طبيعة القطاع الزراعى المصرى كونه قطاع كثيف العمالة ، كما أن معامل الإحلال بلغ حوالى 0,39 مما يشير إلى تدنى إحلال

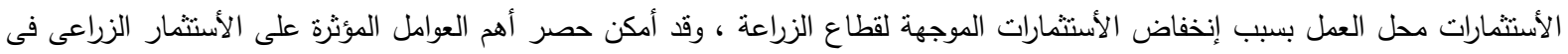

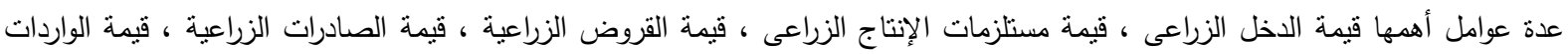

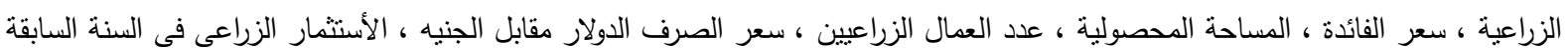

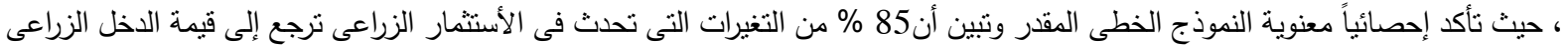

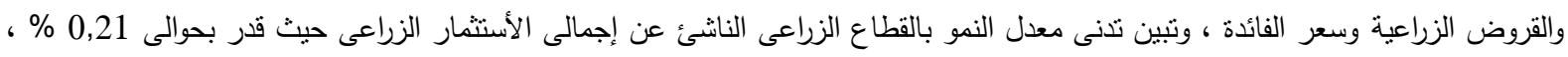
ومنه تبين أنه لتحقيق معدل نمو 1 \% بالقطاع الزراعى فإنه يتطلب تحقيق معدل أستثمار زراعى حوالى 22,28 \% ب أى أى زيادة معدل الأستمار

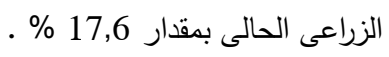

\section{وفى ضوء ما توصل إليه البحث من نتائج فإنه يوصى بما يلى :}

1- وضع سياسة أستثمارية تتتاسب مع سمات القطاع الزراعى المصرى وما يتصف به من تقزم الملكية والتفتت الحيازى وإنخفاض معدلات الأدخار

$$
\text { • الزراعى }
$$

2- أستخدام نظم المعلومات الجغرافية (G.I.S) فى وضع خرائط للإستثمار الزراعى يوضح بها مجالات الأستثمارات الزراعى وترتيب أولوياته

ومساحات الأراضى القابلة للأسنصلاح والمرافق المتاحة.

3- أن ينم تحديد سعر الفائدة على القروض الزراعية فى ضوء حجم الأستثمارات الزراعية المطلوبة .

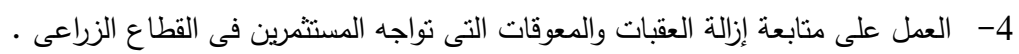

5- زيادة الأستثمارات الزراعية العامة الموجهة لمشروعات البنية التحتية مما بساعد على جذب المستثمرين نتيجة خفض التكلفة الأستثمارية .

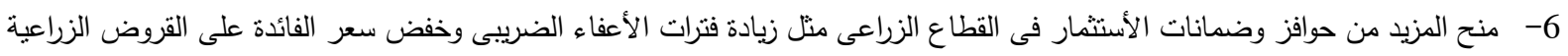
، وبصفة خاصة للمشروعات التى تستخدم التقنية الحديثة مما يساعد على نوطين التقنية الحديثة وتحسين الإنتاجية وزيادة الناتج المحلى لرئ

• الزراعى

المراجع :

1- الجهاز المركزى للتعبئة العامة والأحصاء ، الكتاب الأحصائى السنوى ، أعداد مختلفة .

2- الجهاز المركزى للتعبئة العامة والأحصاء ، النشرة السنوية للتجارة الخارجية ، أعداد مختلفة .

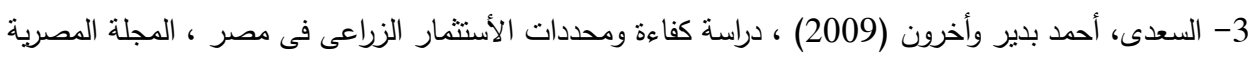

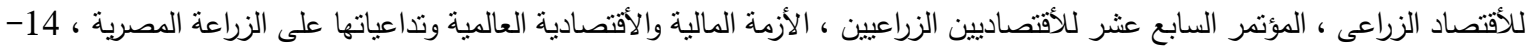

15

4- القريثى، مدحت (2007) ، التتمية الأقتصادية ، نظريات وسياسات وموضوعات ، الطبعة الأولى ، الأردن ، ص 75 ـ

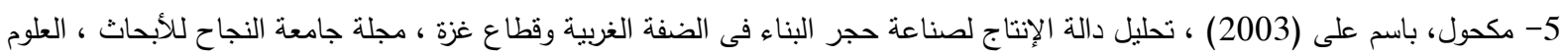

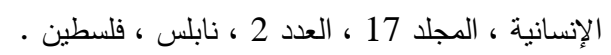

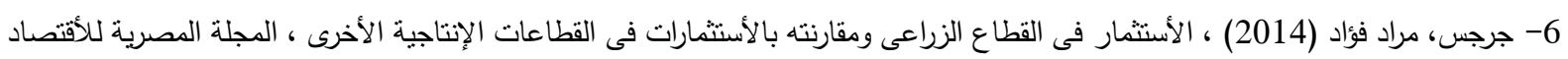

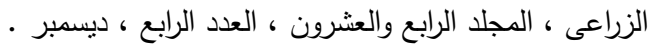

7- ابراهيم، خالد أحمد (2014) ، كفاءة ومحددات الأسنتمار الزراعى فى ج. م. ع. ع. ، المجلة المصرية للأقتصاد الزراعى ، المجلد الرابع والعشرون

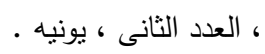

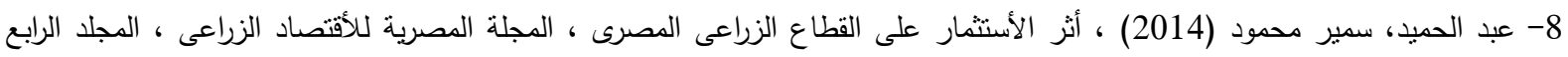

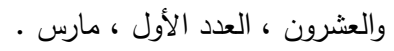

9- عبد الحميد، سوزان مصطفى أحمد (2010) ، دراسة تحليلية للعائد على الأستثمار فى قطاع الزراعة مقارنة ببعض القطاعات الأقتصادية

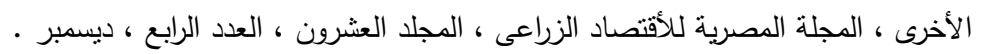

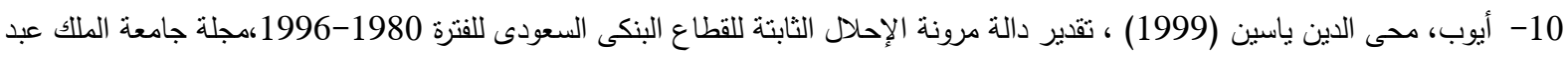

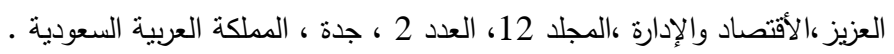


11- مصطفى،عادل محمد وأخرون (2015)، أثر السباسات الأقتصادية الزراعية على حجم الأستثمارات بالقطاع الزراعى المصرى ، المجلة المصرية للأقتصاد الزراعى ، المجلد الخامس والعشرون ، العدد الثانى ، يونيه . Www.cbe.org.eg 12 موقع البنك المركزى المصرى 12

13- وزارة التخطيط والمتابعة والأصلاح الأدارى ، تقارير متابعة الأداء الأقتصادى والأجنماعى ، أعداد مختلفة .

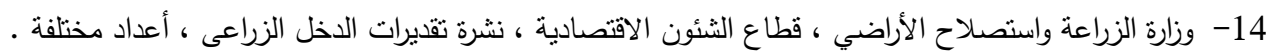

15- Arrow, K,J. Chenery, H, B. Minhas, B, S .Solow, R,M (1961). Capital-Labor Substitution and Economic Efficiency, The Review of Economics and Statistics, The MIT Press, Vol. (43), No. (3), p225-250.

16-Kirchgässner, Gebhard, Wolters, Jürgen, (2007). Introduction to Modern Time Series Analysis, SpringerVerlag Berlin Heidelberg.

17-Todaro, Michael, Smith, and Stephen, (2003), Economic Development, $8^{\text {th }}$ ed., Addison-Wesley-Longman Limited. 
جدول 1. أهم المتغيرات المؤثرة فى الأستنمار الزراعى فى مصر بالأسعار الجارية خلال الفترة (1996/1995 - 2018/2017)

\begin{tabular}{|c|c|c|c|c|c|c|c|c|c|c|c|}
\hline المساحة المدصولية & سنيه/دولار & الفائدة & (مليون عامل) الزراعية & الواردات الزيراعية & الصادرات الززراعية & القروض الزراعية & الإنتاج الزيتلزاعى & الاخل الزراعى (مليار جيه) & الناتج الزراعى (منيار) & الأستثمار الزراعى & السنة \\
\hline 13.71 & 3.40 & 17 & 4.747 & 13.165 & 1.483 & 4.226 & 17.191 & 41.975 & 59.166 & 4.484 & $1995 / 1996$ \\
\hline 13.829 & 3.39 & 16 & 4.82 & 11.883 & 1.137 & 5.065 & 14.182 & 47.088 & 61.27 & 5.192 & $1996 / 1997$ \\
\hline 13.859 & 3.39 & 16 & 4.904 & 11.647 & 1.224 & 6.253 & 15.679 & 47.961 & 63.64 & 8.157 & $1997 / 1998$ \\
\hline 13.939 & 3.40 & 14 & 4.985 & 6.405 & 1.708 & 6.933 & 18.431 & 50.457 & 68.888 & 8.419 & $1998 / 1999$ \\
\hline 13.808 & 3.42 & 13 & 5.069 & 6.917 & 1.845 & 7.728 & 20.969 & 50.695 & 71.664 & 8.133 & $1999 / 2000$ \\
\hline 14.030 & 3.68 & 13 & 5.090 & 7.470 & 1.993 & 8.149 & 21.119 & 53.621 & 74.74 & 8.197 & $2000 / 2001$ \\
\hline 14.350 & 4.45 & 14.1 & 4.980 & 13.963 & 3.400 & 9.126 & 23.772 & 60.488 & 84.26 & 9.594 & $2001 / 2002$ \\
\hline 14.470 & 5.15 & 13.45 & 5.490 & 16.600 & 5.436 & 8.434 & 28.307 & 68.546 & 96.853 & 6.403 & $2002 / 2003$ \\
\hline 14.550 & 6.17 & 13.27 & 6.070 & 17.687 & 7.641 & 8.467 & 29.293 & 82.542 & 111.835 & 7.559 & $2003 / 2004$ \\
\hline 14.900 & 6.02 & 13.35 & 6.040 & 22.257 & 6.251 & 9.305 & 34.083 & 92.888 & 126.971 & 7.42 & $2004 / 2005$ \\
\hline 14.920 & 5.75 & 12.7 & 6.440 & 22.571 & 5.726 & 10.159 & 35.053 & 102.366 & 137.419 & 8.044 & $2005 / 2006$ \\
\hline 15.180 & 5.71 & 13 & 6.970 & 30.241 & 7.958 & 10.799 & 39.638 & 116.307 & 155.945 & 7.792 & $2006 / 2007$ \\
\hline 15.240 & 5.52 & 13 & 7.120 & 44.738 & 14.348 & 11.024 & 48.911 & 136.756 & 185.667 & 8.072 & $2007 / 2008$ \\
\hline 15.500 & 5.53 & 11 & 6.910 & 38.341 & 18.851 & 6.456 & 51.384 & 138.054 & 189.438 & 6.862 & $2008 / 2009$ \\
\hline 15.330 & 5.53 & 11 & 6.770 & 51.223 & 21.092 & 6.025 & 58.638 & 150.713 & 209.351 & 6.743 & $2009 / 2010$ \\
\hline 15.350 & 5.82 & 11 & 6.860 & 72.363 & 22.670 & 8.570 & 70.313 & 179.676 & 249.989 & 6.834 & $2010 / 2011$ \\
\hline 15.560 & 6.09 & 12 & 6.400 & 96.299 & 27.140 & 8.154 & 76.608 & 190.816 & 267.424 & 5.371 & $2011 / 2012$ \\
\hline 15.490 & 6.05 & 11 & 6.740 & 99.211 & 34.890 & 7.237 & 78.611 & 203.824 & 282.435 & 8.384 & $2012 / 2013$ \\
\hline 15.680 & 6.94 & 11.9 & 6.740 & 115.065 & 36.711 & 8.986 & 81.71 & 223.704 & 305.414 & 11.627 & $2013 / 2014$ \\
\hline 15.640 & 7.14 & 12.2 & 7.310 & 116.516 & 37.217 & 11.125 & 94.631 & 224.918 & 319.549 & 13.414 & $2014 / 2015$ \\
\hline 15.801 & 7.81 & 12.5 & 7.440 & 146.897 & 49.267 & 11.419 & 107.925 & 256.015 & 363.94 & 16.279 & $2015 / 2016$ \\
\hline 16.038 & 14.81 & 15.7 & 6.51 & 245.628 & 86.345 & 9.618 & 142.409 & 329.303 & 471.712 & 21.863 & $2016 / 2017$ \\
\hline 16.061 & 17.73 & 18 & 5.629 & 257.555 & 87.113 & 14.158 & 175.602 & 325.087 & 500.689 & 48.386 & $2017 / 2018$ \\
\hline 14.923 & 6.21 & 13.40 & 6.088 & 63.680 & 20.932 & 8.583 & 55.846 & 137.991 & 193.837 & 10.575 & المتوسط \\
\hline
\end{tabular}

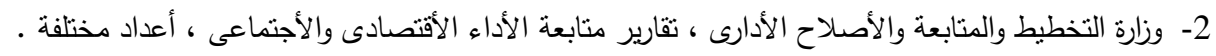

3- وزارة الزراعة وأستصلاح الأراضى ، قطاع الثئون الأقتصادية ، نشرة تقديرات الدخل الزراعى . 


\title{
Analytical study of Agricultural Investment in Egypt
}

\author{
Dr.Mahaba Abd El-Moety El-Sayed Ahmed Mahaba \\ Dr. Mohamed Ali Mohamed Sokar \\ Department of Economic Studies-Socio-Economic Division-Desert Research Center \\ Corresponding author: mahaba_agr11@yahoo.com
}

\begin{abstract}
Summary
Investments are considered one of the most important means to implement agricultural development programs in Egypt, which in turn helps to increase productive capacities and thus increase the rates of capital accumulation in the agricultural sector and thus increase the proportion of the agricultural sector's contribution to GDP. The main objectives of the research were to identify the current state of national and agricultural investment and the local and agricultural output, measure the efficiency of agricultural investment by estimating some economic indicators, and measure the impact of agricultural investment on the growth rate of the agricultural sector using the Harrod-Domar model during the period (1995/1996-2017/2018). The research reached several results, including: that agricultural investments, both public and private, increase annually in an amount that is not statistically significant, and that the overall agricultural output decreases annually by a statistically significant amount estimated at about 0.004 billion pounds annually, while the private agricultural output increases annually by a statistically significant value estimated by 4.95 billion pounds annually, and therefore the value of agricultural production increases annually by a statistically significant amount of about 4.94 Billion pounds annually, with regard to the efficiency of agricultural investment in Egypt, it became clear through the evaluation of efficiency indicators that achieve economic efficiency for agricultural investments in general, as it was clear that the private sector outperformed the public sector in achieving economic efficiency of investments, It was evident from the estimation of the relationship between agricultural investment and the value of agricultural production in Egypt using the constant elasticity of substitution (CES) function that the elasticity of production in relation to work is higher than the elasticity of production in relation to investments, i.e. production depends on the work element, as the importance of the labor component increases in increasing production compared to investments, this corresponds to the nature of the Egyptian agricultural sector as it is a labor-intensive sector, and the replacement factor reached about 0.39 , which indicates the low replacement of workplace investments due to the decrease in investments directed to the agricultural sector, a study of the factors affecting agricultural investment showed that the value of agricultural income, agricultural loans and the interest rate are responsible for explaining that $85 \%$ of the changes that take place in it have been statistically confirmed by the significance of the estimated linear model. The growth rate of the agricultural sector, resulting from the total agricultural investment, was found to be low, as it was estimated at $0.21 \%$. From it was found that to achieve a $1 \%$ growth rate in the agricultural sector, it requires achieving an agricultural investment rate of $22,28 \%$, i.e. increasing the current agricultural investment rate by $17.6 \%$.
\end{abstract}

In light of the results of the research, it is recommended that:

1- Establishing an investment policy commensurate with the characteristics of the Egyptian agricultural sector and its stunting of ownership, fragmentation of property, and low rates

of agricultural savings.

2- Using Geographic Information Systems (G.I.S) in developing agricultural investment maps showing areas of agricultural investment, prioritizing it, reclaimed land areas and available facilities.

3- That the interest rate on agricultural loans be determined in light of the volume of agricultural investments required.

4- Working to follow up the removal of obstacles and obstacles facing investors in the agricultural sector.

5- Increasing public agricultural investments directed to infrastructure projects, which helps to attract investors as a result of reducing the investment cost.

6- Granting more incentives and guarantees for investment in the agricultural sector, such as increasing the periods of tax exemption and reducing the interest rate on agricultural loans, especially for projects that use modern technology, which helps to settle modern technology, improve productivity, and increase agricultural production.

Key words : Agricultural investment, Influencing factors, Growth rate, Agricultural sector. 